\title{
REINVENTING
}

\section{THE MEDIA FRANCHISE:}

CONTEXT, MEANING AND DISCOURSE

\author{
by \\ Felan Parker, BA (Hons.) \\ A thesis submitted to the Faculty of \\ Graduate Studies and Research in Partial fulfillment \\ of the requirements for the degree of \\ Master of Arts \\ in Film Studies
}

Carleton University

OTTAWA, Ontario

April 2009

(C) 2009, Felan Parker 
Library and

Archives Canada

Published Heritage

Branch

395 Wellington Street

Ottawa ON K1A 0N4

Canada
Bibliothèque et

Archives Canada

Direction du

Patrimoine de l'édition

395 , rue Wellington

Ottawa ON K1A 0N4

Canada

Your file Votre référence

ISBN: 978-0-494-51968-4

Ourfile Notre référence

ISBN: 978-0-494-51968-4

NOTICE:

The author has granted a nonexclusive license allowing Library and Archives Canada to reproduce, publish, archive, preserve, conserve, communicate to the public by telecommunication or on the Internet, loan, distribute and sell theses worldwide, for commercial or noncommercial purposes, in microform, paper, electronic and/or any other formats.

The author retains copyright ownership and moral rights in this thesis. Neither the thesis nor substantial extracts from it may be printed or otherwise reproduced without the author's permission.
AVIS:

L'auteur a accordé une licence non exclusive permettant à la Bibliothèque et Archives Canada de reproduire, publier, archiver, sauvegarder, conserver, transmettre au public par télécommunication ou par l'Internet, prêter, distribuer et vendre des thèses partout dans le monde, à des fins commerciales ou autres, sur support microforme, papier, électronique et/ou autres formats.

L'auteur conserve la propriété du droit d'auteur et des droits moraux qui protège cette thèse. $\mathrm{Ni}$ la thèse ni des extraits substantiels de celle-ci ne doivent être imprimés ou autrement reproduits sans son autorisation.
In compliance with the Canadian

Privacy A'ct some supporting forms may have been removed from this thesis.

While these forms may be included in the document page count, their removal does not represent any loss of content from the thesis.
Conformément à la loi canadienne sur la protection de la vie privée, quelques formulaires secondaires ont été enlevés de cette thèse.

Bien que ces formulaires aient inclus dans la pagination, il n'y aura aucun contenu manquant.

\section{Canadä}




\begin{abstract}
This thesis presents a framework for the conceptualization and analysis of media franchises. Traditionally understood to be an industrial practice, I argue that franchises are discursive constructs, not unlike genres and nations. Such constructs do not have any singular fixed meaning, but rather represent webs of discourse that are deployed by a wide variety of different users in different contexts and for different purposes. The analysis of these discourses (including those considered to be outside of the franchise canon of fictional texts, such as marketing and fan culture), can yield valuable insights into the meaning and function of franchises in specific contexts. In this conceptualization, the media franchise can be situated in relation to broader theories of meaning, as one of many overlapping discursive constructs according to which the production of meaning is structured.
\end{abstract}




\section{ACKNOWLEDGEMENTS}

Thanks to George McKnight for planting the seed, and to Marc Furstenau for cultivating it. 


\section{TABLE OF CONTENTS}

1. Introduction 1

2. Chapter One: Another Critical Redefinition 9

3. Chapter Two: The "Official" Version - Dominant Franchise Discourse 34

4. Chapter Three: Beyond Canon - Apocryphal Franchise Discourse 59

5. Chapter Four: Beyond Text - Ephemeral Franchise Discourse 85

6. Conclusion 104

$\begin{array}{ll}\text { 7. Bibliography } & 107\end{array}$ 


\section{INTRODUCTION}

Your universe hangs within a structure of universes, a thing almost like a snowflake.

This is the shape of reality. ${ }^{2}$

Somebody once related a story to me about an academic presenting a paper at a fan-oriented comic con on the questionable treatment of masculinity in Superman comics. The response to the paper from the assembled fans was (perhaps predictably) largely negative, and during the question period one fan perfectly summed up the problem with the lament, "why can't you just let us like Superman?!" Comic book writer Stan Lee (who co-created Spider-Man, The X-Men, Iron Man and other iconic Marvel superhero characters, and thus originated some of the most lucrative, long-lasting and far-reaching media franchises in history) used to address readers as "True Believers" in his editorial page columns. The term is apt: the dedication and conviction of fans (especially comic book fans) can be remarkably similar to religious belief. Franchises seem to encourage this kind of fandom, by presenting True Believers with a vast range of stories, characters, media and products to engage with, and can engender passionate zeal. This thesis is about media franchises. Much as the study of religion can create problems for students who find it difficult to reconcile faith with rigorous academic inquiry, fandom can be a serious roadblock to the study of franchises. Attachment to a particular character, text or fictional universe can cause us to become overly defensive and reject analyses that do not conform to our personal vision of the franchise, or are perceived as a threat to our enjoyment or.

\footnotetext{
Warren Ellis, Planetary: Vol. 1 - All Over the World and Other Stories (New York: DC Comics, 2000), 95.

2 Ibid, 19.
} 
appreciation of it.

The comic con anecdote highlights a variety of misconceptions about - and potential problems with - the study of popular franchise media. First and foremost, the story indicates the commonly perceived disconnect between academics who take things too seriously and carefree fandom: "you" the academic is distinct from "us," the fans. There is an assumption in the story that the academic cannot also be a fan; he or she has crossed an imaginary line and become something other. The academic's research is seen to be an assault on fandom and on Superman himself. Needless to say, this is not a productive state of affairs for either academia or for fans. Let us return to my above analogy to religion. Although for some faithful believers who are also scholars, academic religious studies are highly problematic, for many they are not. Regardless of the approach - theological, philosophical, historical, sociological - there does not have to be dissonance between faith and reason. Indeed, for many scholars of religion the concepts are fundamentally different, and thus there is no need to reconcile the two they exist apart from one another. One can have faith on the one hand and study religion on the other without subverting or losing either. I believe that the same is true of fandom and franchise studies. It is fully possible to be a fan of Superman and simultaneously engage critically with superhero comics, or to enjoy The Lord of the Rings while simultaneously analyzing it, because they are not binary opposite activities. Rather, I would argue that fandom enriches academic study and vice versa, offering personal experience to draw upon in addition to research, as well as expansive new insights into the object of fandom. Media scholar Henry Jenkins, for his part, self-reflexively refers to 
himself as an "aca-fan," a sort of Utopian hybrid of the two roles. Jenkins, along with others including Kristin Thompson and Will Brooker who I will discuss in this thesis, is exemplary of this approach, effectively combining active engagement with critical distance to produce truly compelling works of scholarship on popular media franchises. In addition to illustrating this particular quandary of popular media studies, however, the comic con story demonstrates clearly that franchises are powerful, compelling concepts that can mean many things to many different people. The fan in the story is both personally invested in a particular vision of the Superman franchise, and representative of a larger community of fans who are similarly (but not necessarily identically) invested. For the academic in the story, the Superman franchise is indicative of larger questions about representation. For industry representatives at the comic con, the Superman franchise is a valuable brand name and a highly profitable collection of consumer products. And yet these disparate understandings of what the Superman franchise is are not insular: the fan voraciously consumes the Superman products peddled by the industry; the academic's research is necessarily concerned with the cultural reception of Superman by fans and with the industrial structures in which the franchise is produced; and the industry relies on the dedication of fans to the fictional elements of the franchise. Additionally, the academic and industry representatives might well themselves be personally invested fans of Superman. Each of these overlapping discourses constitutes a definitive part of the Superman franchise, and the story raises a simple question: what are media franchises? This thesis is intended to answer that question, and the related question, how are we to study media franchises? As to the first question, I will 
argue that franchises are networks of discourse akin to genres. Imagine a complex web, composed of various elements and defined by the relationships between those parts. Some of the elements are fictional texts in the traditional sense: films, television shows, comic books, novels and so on. Some elements are newer forms such as video games, fan creations and DVD/Blu-ray special features. Other elements still are not textual or fictional at all in the traditional sense, such as marketing and promotional materials, websites, online communities, and merchandise. This vast range of elements are nodes in the web. Between these nodes are an exponentially larger number of connecting lines, forming the web itself. Making the web even more complex is the fact that there are many different kinds of connecting lines, representing the diverse approaches to the network itself by different groups of people, in different contexts. Overlapping and interacting, the lines signify discourse and, as noted above, perform a definitive function in the network, creating a multitude of meanings by drawing connections between the nodes in every conceivable pattern. This is what I believe franchises "look" like: all the discourses that have ever existed in relation to an idea or concept, mapped onto the same imaginary network and called a franchise.

Needless to say, if media franchises are so complicated, they present a daunting object of study. I contend that in order to properly account for that complexity, they must be studied as discursive constructs. As I have demonstrated above, franchises are much more than collections of branded texts, and therefore the study of franchises must not be limited to textual analysis, and should acknowledge the diversity of other discourses that constitute and define the network. By the same token, research into media franchises 
cannot be limited to those elements deemed to be canonical and authentic, although those discourses are prevalent among both fans and the industry. Additionally, given how variable the meaning of franchises is, depending on context and use, analyses of franchise discourse must be clearly situated temporally and pragmatically. Throughout this thesis, with reference to a broad range of popular franchises, I will argue that in order to properly approach the concept, we must pay close attention to the discursive processes by which meaning is made by various groups of users, and extend our understanding of franchises far beyond the dominant discourses of canon and text. The franchises I will examine have mostly been chosen due to their popularity and financial success, and are the kinds of franchises that garner massive profits for the industry, draw large audiences, engender strong fan culture, and are composed of many different elements. In short, these are well-known examples of the media franchise that embody the concepts and ideas this thesis is designed to theorize.

I wish to comment briefly on some of the terminology used in this thesis. The term "media franchise" is not a clear-cut term, but I suggest is generally understood to mean a collection of texts and products linked by common branding. In the course of my arguments, I hope to expand this industry-oriented definition. Other terms that are used by theorists like Jenkins and David Bordwell to describe related or analogous concepts such as "storyworld" and "universe" I find ineffective because they explicitly stress the fictional elements of franchises, when in fact I hope to demonstrate that franchise discourse is far from exclusively concerned with fiction and narrative. Although I will use the terms "media franchise" and "franchise" interchangeably for most of this thesis, it 
should be noted that the term "franchise" has a more general meaning outside of the entertainment industry, which I will discuss in Chapter One. I also wish to clarify the distinction between a franchise and a "series." As noted above, a franchise can include many different parts, and may contain any number of different series. Therefore, while "the Superman franchise" refers to the overall discursive network, "the series beginning with Superman: The Movie (1978)" would refer to a particular collection or sequence of texts within the network. For the purposes of this thesis, the names of franchises will appear unformatted, while the titles of specific franchise texts will appear in italics, as above. Several other terms to which I will return frequently are "the industry," "fans," and "general" or "mainstream audiences." These concepts are deliberately and necessarily vague, as I intend to make theoretical arguments that apply to media franchises generally and are not contingent on the particular industrial and sociological composition of any one franchise. "The industry" refers to the assortment of companies, conglomerates and subsidiaries that control the "official" version of a given franchise; "fans" refers to those consumers who self-identify as such in relation to a given franchise; "general" or "mainstream audiences" refers to all other consumers who may engage with a franchises to varying degrees, but do not self-identify as fans. These should not be taken as empirical categories, but stand for broad concepts in order to help illustrate my largely theoretical arguments.

In Chapter One, I will provide a brief overview of the history of franchises as a general business concept, as well as an assessment of what the term is commonly understood to mean in popular discourse. Additionally, I will critique the ways in which 
franchises and franchise texts have been analyzed in film and media studies, in particular questioning the utility of purely industrial and economic accounts of the concept. This will segue into a survey of the literature that will inform my own account, designed to situate this thesis in relation to broader theoretical concerns and ideas. In particular, I will draw an analogy between franchises and other discursive constructs such as genre and nation, which due to their conceptual similarity will help to characterize the media franchise. This survey will establish the groundwork for the final section of Chapter One, in which I will articulate my basic thesis, as described above, in further detail.

Chapter Two is chiefly concerned with the concepts of canon and continuity, through which franchise texts and meanings are ordered according to their perceived authenticity. In particular, I am concerned with how the industry and fans (some of the most powerful and adamant users of franchises) discursively establish canon and continuity. I will emphasize the interaction between various notions and versions of "official" status and the franchise canon, and in doing so will demonstrate that in spite of the drive to order the complexities of franchise networks, canon and continuity represent an illusory coherence that masks the fundamental incoherence of franchise discourse and meaning. Finally, I will argue that as scholars we must not limit ourselves to the restrictive vocabulary of "official" and "unofficial," and instead must cultivate a more nuanced understanding of canon and continuity as discourse.

In Chapter Three, I will pursue this argument to its logical conclusion by examining the notion of franchise apocrypha - those texts that, for a wide variety of reasons, are not considered to be part of the "official" canon. In particular, I will discuss 
texts that have been discursively removed from the canon by fans or the industry, that exist as part of a parallel "official" version, and that self-reflexively comment upon or otherwise are positioned in relation to the franchise network, but are still considered to be non-canonical. In doing so, I will demonstrate how such apocryphal texts can nevertheless be extremely valuable objects of study, as they highlight the meaning of a franchise in certain contexts that are otherwise difficult to analyze. Additionally, I will argue that the meanings created by franchise apocrypha contribute to and expand franchise discourse in significant ways.

Lastly, in Chapter Four, I will extend my account of media franchises even further, beyond both canon and text to include what I have termed franchise ephemera aspects of a franchise that are by nature fleeting and understood to be peripheral, such as marketing, merchandise, fan discourse, etc. By way of an extended case study, I will bring the thesis full circle, drawing together all my arguments into the analysis of a particular ephemeral aspect of the Die Hard franchise. 


\section{CHAPTER ONE:}

\section{ANOTHER CRITICAL REDEFINITION}

According to The Economics of Franchising by Roger D. Blair and Francine Lafontaine, the term franchise has its origins in medieval societies, in which rights or privileges, such as maintaining civil order and collecting taxes in a certain area, or building roads, were granted by sovereign powers to individuals or groups.. The individual or group would pay the sovereign some portion of the profit or yield of the activity, hence the modern term "royalty." In other words, the sovereign profits by allowing individuals or groups to pay for the right and privilege to act in the name of the sovereign, effectively branding the activity as official and legitimate. Although franchising has existed in various forms throughout history, the current understanding of the word becomes common business practice in the years following World War II. ${ }^{4}$ The International Franchise Association describes the contemporary version of the business model thusly:

Franchising is a method of distributing products or services. At least two levels of people are involved in a franchise system: (1) the franchisor, who lends his trademark or trade name and a business system; and (2) the franchisee, who pays a royalty and often an initial fee for the right to do business under the franchisor's name and system. Technically, the contract binding the two parties is the "franchise," but that term is often used to mean the actual business that the franchisee operates. ${ }^{5}$

\footnotetext{
Roger D Blair and Francine Lafontaine, The Economics of Franchising (New York: Cambridge University Press, 2005) 3.

4 Blair and Lafontaine, 4.

5 International Franchise Association, "Frequently Asked Questions About Franchising," http://www.franchise.org/industrysecondary.aspx?id $=10008$.
} 
A franchise, therefore, allows the franchisor to maintain a much larger public presence, reaping the benefits of royalties without the risk of investing money in each individual operation; for the franchisee, it is an opportunity to capitalize on a familiar brand name and proven method of doing business. As in its medieval form, franchising provides direct benefits to both parties. Although a wide range of businesses are and have been organized according to the franchise model, some of the most common franchises are retail chains, including fast food restaurants and grocery stores, identified sometimes by the name of the franchisee: Hartman's Independent Grocer, for example. Sports franchises, as they are sometimes called, operate in much the same way: the league functions as franchisor to grant the right to franchisees to maintain official teams in different areas. Over the course of the twentieth century, however, the term franchise has come to signify a parallel concept in the entertainment industry, similar in principle but very different in practice. Within a media franchise, one central company acts as the franchisor, licensing either the branding or content of a property to other companies (or subsidiaries of the same conglomerate) to create and sell ancillary products. On this basic level, media franchises function in much the same way as those in other industries: in 1977 Lucasfilm, the franchisor, licensed Kenner Products, the franchisee, to create Star Wars action figures and other toys, and Kenner in turn paid royalties to Lucasfilm. However, in contemporary use the term franchise has a much broader meaning, extending beyond the specific practice of franchising to describe transmedia brands of all kinds the Star Wars franchise, therefore, refers not only to franchised products but is a blanket term for all Star Wars-branded media and products, including those that are not actually 
franchised, such as the "official" Star Wars films. In this sense, "media franchise" can refer to any grouping of media and products categorized by brand, regardless of whether franchising as a business practice is involved.

By this definition, franchises have been important to the American entertainment industry throughout the modern era, and properties that span media such as Sherlock Holmes or Tarzan can be seen as early examples. In the culture of convergence that has emerged since the late 1970 s, however, they are a driving force, creating many millions of dollars in profits for the companies and conglomerates that own and market them. Although primarily associated with properties such as Star Wars or The Lord of the Rings, media franchises can also be based around news, non-fiction and other media not necessarily geared towards narrative or fiction (consider the the Discovery Channel's Planet Earth franchise, or the "For Dummies" line of instructional books and other tools). Generally, however, franchises are understood to be categories for products and media, linked by common features and branding, usually centred around a particular fictional character or concept, such as Superman or the Transformers universe. For the industry, franchises are a framework for creating and marketing media and products. Like other brands, they are a way of establishing familiarity among consumers. Some more casual consumers may only follow certain parts of a franchise, experiencing it largely via individual feature films or novels. For these consumers, a franchise might be seen as little more than a series of narratively linked texts. The most die-hard fans, on the other hand, might align themselves with a franchise as a whole, voraciously consuming every available branded object. In many cases for fans, franchises are seen to represent fictional 
universes with which to engage, that "exist" in imagination beyond the products and media that constitute them. Evidently, the current meaning of the term is not set in stone, and is dependent on use and context, but broadly speaking franchises are understood to indicate a particular set of features and establish certain expectations for consumers familiar with the brand.

Having briefly highlighted the history of franchises as an industrial concept, and assessed the contemporary understanding of what constitutes a media franchise, I will now examine how the concept of franchise has been approached by scholars in film and media studies. In the academy, franchises are largely understood to be an aspect of the industrial organization of the entertainment business, with studies and historical accounts tending to emphasize the purpose and function of franchises within the Hollywood "machine." The term itself has seen limited use, and the concept is rarely the direct focus of research. Franchises are often noted in overviews of the contemporary film industry, but the specific emphasis is often on films and other texts as opposed to the many other products and ideas that constitute a franchise. By the same token, fandom studies are by design more concerned with the culture surrounding franchises rather than with the concept itself. Often, franchise films are treated simply as individual texts, and are studied out of context without considering the implications of a text being part of a franchise. The notion of franchise has never been theorized as a critical concept within film and media studies, and has remained a loose object of study rather than a framework for study. In this section I will outline some of the most common academic approaches to 
franchises, indicating the limitations of each.

Generally, franchises are linked to the development of the blockbuster and the "New Hollywood" in narratives of cinema history. Billy Jack (1971) is occasionally cited as an early example of the blockbuster, but more often Jaws (1975) is considered the seminal example of the form. Star Wars (1977), however, is almost invariably positioned as the first true blockbuster, and indeed the prototype for media franchises to come: George Lucas' deal with $20^{\text {th }}$ Century Fox allowed him to collect profits on ancillary licensed products, which made him a rich man and demonstrated the potential value of the franchise approach. ${ }^{6}$ Although earlier media properties, such as The Godfather (1972) and Star Trek, employed similar tactics of promotion and cross-marketing, general consensus seems to suggest that because Star Wars was licensed on such a wide scale, it should be seen as the first film to fully embrace the new modes of production of the blockbuster era. The franchise, therefore, is described in most film histories as a business practice that captured the zeitgeist of the time - the logical extension of blockbuster production in the late 1970 s and through the 1980 s, and a clear and easy way to maximize profits. The scale and success of franchises in the blockbuster era, it seems, sets them apart from analogous forms in the classical studio system.

Economic accounts of the contemporary entertainment industry, such as Janet Wasko's 2003 book How Hollywood Works, situate franchises firmly within the system as a key part of the industrial organization of Hollywood. Wasko refers to herself as a political economist, concerned with the study of film as a commodity produced by a

6 Justin Wyatt, High Concept: Movies and Marketing in Hollywood (Austin, Texas: University of Texas Press, 1994) 111; Kristin Thompson and David Bordwell, Film History: An Introduction (Madison, Wisconsin: McGraw Hill, 2003) 522, 530; Thomas Schatz, "The New Hollywood," in The Film Cultures Reader, ed. Graeme Turner (New York: Routledge, 2002), 190-195. 
specific industrial structure, and offers critiques of the systems that she uncovers. ${ }^{7}$ In studies such as Wasko's, franchises are but one of many means of achieving the same goal: the highest possible profits. Franchises, therefore, are understood here in much the same way as they are in the industry, as a highly effective form of marketing and product differentiation. Certainly, in the context of an economic analysis, this makes sense and is sufficient, but the definition is lacking if we ask what might be different about franchise media when compared to other media (how is Star Wars different from a similar but unfranchised film like Outland [1981], for example) or how the concept is approached and interpreted by audiences and critics. If the industry makes franchise films in order to reap the rewards of a pre-sold property, the reception of these properties must surely affect the industry, but these questions are left largely unanswered by Wasko and other researchers concerned with Hollywood economics. Franchises are not treated as a distinct form within the industry or culturally, but as an incarnation of the broad underlying philosophy and business practice of Hollywood.

If these common historical and economic approaches to media franchises are insufficient for my purposes, it is understandable — for these studies, franchises are simply one part of a larger project, that of tracing the development and organization of Hollywood as a whole industry. This does not in and of itself constitute a problem. The problem here is that beyond this version, there is virtually no academic conception of what franchises are and how they work. Franchises are viewed almost exclusively as an industrial phenomenon and mode of production, which presents serious limitations to an understanding of the larger meaning and significance of franchises and ignores a variety

7 Janet Wasko, How Hollywood Works, (London, England: SAGE Publications Ltd., 2003) 7-8. 
of important questions. How are franchises used by audiences and fans? How do we reconcile the many different versions of the same ideas, narratives and concepts reiterated within franchises? What, if anything, is different about franchise texts compared to other texts? How do we account for the non-textual elements of a franchise, such as marketing and merchandise? These are not exclusively historical questions, nor are they exclusively economic, and the commonly accepted definition of franchises as an entertainment business practice does not lead us to satisfactory answers. The key question continues to be, how are we to study media franchises?

This thesis is intended to complicate the conventional account of media franchises described above, and in doing so to rehabilitate the concept of franchise as a useful framework for study. To borrow Justin Wyatt's terminology from the book High Concept: Movies and Marketing in Hollywood, this is a critical redefinition. Wyatt proposes "to offer a more precise definition of high concept through tracing the historical, institutional and economic forces that have helped to shape this particular kind of commercial filmmaking." Much as Wyatt recasts the previous industry- and journalism-specific concept of "high concept" as a distinct film style, mode of production, marketing strategy and cultural phenomenon, I intend to develop a more precise definition of media franchises as a particular form of discursive network, and to present an approach to these texts and meanings that will help us make more sense of them. In order to do so, I must expand significantly upon the standard industry-oriented definition of franchise and consider a wide variety of other discursive factors, including "official" notions of canon

$8 \quad$ Wyatt, 7. 
and continuity, apocryphal and otherwise non-canonical texts and discourses, fan culture, promotional materials and other ephemeral elements of franchises, and the constantly shifting nature of franchises. Refuting the conventional account of franchises as a primarily industrial concept, I posit franchises as elaborate, complex networks of meaning that exist in many different forms in many different contexts. In this section, I will situate my argument within a variety of other research that both explicitly and implicitly informs it, demonstrating how franchises can be understood as much more than a simple means to an economic end.

There is are exceptions to every rule, and Kristin Thompson's The Frodo Franchise: The Lord of the Rings and Modern Hollywood is one of the few scholarly books that deals directly and primarily with the concept of franchises, as opposed to the more general historical and economic studies noted above. Thompson's approach incorporates elements of both, and the book is positioned as an industrial history of the franchise's development from original optioning to DVD releases and beyond. ${ }^{9}$ Unlike conventional accounts, however, Thompson presents a much more detailed and nuanced study of the Lord of the Rings franchise, including extensive discussions of the marketing, branding and merchandising strategies employed, and the many faces of Lord of the Rings fandom in relation to the most recent film adaptations. Thompson also includes an overview of the broader history of the franchise that emerged around J. R. R. Tolkien's novels, reminding us that franchises can span many generations, changing dramatically over time, and are not by any means a new phenomenon (the James Bond

9 Kristin Thompson, The Frodo Franchise: The Lord of the Rings and Modern Hollywood, (Berkeley, California: University of California Press, 2007). 
franchise being another illustrative example).${ }^{10}$ By expanding the traditional emphasis on industrial organization and production history to include serious considerations of other aspects of the franchise, Thompson demonstrates a historical approach to franchises that is remarkably exhaustive. Thompson thus implicitly recognizes that what is made peripheral in other accounts of media franchises - ephemera such as marketing and merchandising materials, cultural reception, fan culture and creations, media coverage, special events and even public policy ${ }^{11}$ - is in fact central to the meaning of media franchises. ${ }^{12}$ Although Thompson at times avoids specific analyses of texts and meanings within The Lord of the Rings in favour of historical documentation, The Frodo Franchise remains an effective demonstration of a broader conceptualization of media franchises, and informs in many ways my own theoretical project.

Henry Jenkins' contemporary media studies touchstone, Convergence Culture: Where Old and New Media Collide is less specifically concerned with franchises, but is nevertheless concerned with the ways in which media and culture function in the digital age. According to Convergence Culture, franchising is "the coordinated effort to brand and market fictional content within the context of media conglomeration." Convergence, on the other hand, is in Jenkins' words "a process or series of intersections between different media systems. ${ }^{.14}$ For Jenkins, therefore, media franchises (as we generally understand them) are a principally modern phenomenon, uniquely suited to a

10 Thompson, 10-11, 17-22.

"Thompson, 282. (The relationship between the New Zealand government and the franchise is discussed at length in Chapter 10 of The Frodo Franchise.)

12 Thompson, 165.

13 Henry Jenkins, Convergence Culture: Where Old and New Media Collide (New York: NYU Press, 2006) 285.

14 Jenkins, 282. 
media landscape defined by increasing convergence. In such a landscape, Jenkins argues, it is only logical that the industrial principles of synergy and convergence (the symbiotic horizontal integration of various elements of a whole) be applied to narrative media. ${ }^{15}$ Citing examples from the Matrix franchise, Jenkins demonstrates how the fictional postapocalyptic world is conveyed across many different media and platforms, ranging from the films themselves to websites, comic books, video games, and animated short films. "Transmedia storytelling," he argues, is an important feature of both contemporary franchises and of convergence culture more generally, that encourages active engagement and an "encyclopedic impulse" to dig ever deeper into the branded fictional universes created by franchise media. ${ }^{16}$ By incorporating narrative gaps and excesses into franchise texts, producers are able to leave room for future products and extensions of the storyworld, and for fans to fill in the blanks with "unofficial" contributions. ${ }^{17}$

What is important about Jenkins' approach is his willingness to look beyond the industrial aspects of convergence to consider accompanying changes in aesthetics and reception. Where he falters, however, is in suggesting that coherent, synergistic transmedia storytelling is the ideal for all franchises, and that each individual entry into a franchise should contribute equally and uniquely to the whole. ${ }^{18}$ This ameliorative prescription is inconsistent with the reality of most media franchises - which more often than not create increasingly incoherent fictions - and with the aesthetics of franchise media (consider, for example, the many convoluted parallel instances of any given

15 Jenkins, 292.

16 Jenkins, 96.

17 Henry Jenkins, "Transmedia Storytelling 101," Confessions of an Aca-Fan, http:/henryjenkins.org/2007/03/transmedia_storytelling 101.html.

18 Jenkins, 96. 
superhero that are embraced simultaneously by fans). ${ }^{19}$ For academic purposes, this incoherence should not be considered a failing, but rather should be theorized and studied as an inevitable part of any franchise. Jenkins additionally does not fully acknowledge the place of non-narrative elements in the Matrix franchise: how does a downloadable screensaver that mimics the dropping green code featured throughout the franchise fit in to the transmedial story being told? Jenkins suggests that most merchandising and licensed products are "redundant" to the larger franchise due to their lack of narrative contribution and coherence. ${ }^{20}$

Later in the same chapter, however, Jenkins cites the example of Boba Fett, a character in the Star Wars franchise who gained most of his initial popularity through toys and other fictionally redundant, non-textual merchandise. ${ }^{21}$ Like other scholars concerned with fandom studies, throughout Convergence Culture, Jenkins discusses at length the importance of fan cultures in context of media convergence, and notes the degree to which audiences are engaged in the process of meaning making, whether through literal participation such as fan fiction, or simply through active interpretation and discourse. ${ }^{22}$ The multiplicity of interpretations and versions engendered by any franchise (and in the extreme by franchises such as The Matrix, as Jenkins himself demonstrates) are a valid and essential aspect of their meaning. ${ }^{23}$ Evidently, these

19 See Dru H. Jefferies, "Convergence Culture and the Caped Crusader: Batman and the Environment of New Media" (paper presented at the annual Film Studies Association of Canada Graduate Colloquium, University of Toronto, February 15-17, 2008). In this paper, Jeffries suggested that the Batman franchise c1989 was a "failed" attempt at transmedia storytelling due to its lack of a coherent storyworld. This, although fully consistent with Jenkins' theory, struck me as a fundamental misunderstanding of superheroes, franchises and fandom, all of which thrive upon this very incoherence.

22 Jenkins, 131.

23 Jenkins, 100. 
seemingly peripheral materials can play an important role in the elaboration and meaning of a franchise, and therefore cannot be ignored in the study of media franchises as a concept. (Thompson, for her part, is quick to acknowledge these ephemeral aspects as valid and meaningful elements of the Lord of the Rings franchise.) In order to understand media franchises, therefore, this incoherent diversity of meaning must be taken into consideration. In spite of these criticisms, however, Jenkins' book establishes some useful frameworks for this project, especially in its wide grassroots-to-corporate scope, and its emphasis on the complex relationships between media, as well as between users of those media.

Jusin Wyatt's study of high concept films is also an important source for this thesis. In addition to my appropriation of his "critical redefinition" methodology, High Concept is a valuable starting point for any study concerned with the contemporary film and entertainment industry. Most importantly, Wyatt treats individual films and film style as only one part of a process that includes industrial organization, marketing and merchandising. High concept films, he suggests, are completely integrated with their marketing, and therefore marketing and merchandise must be considered alongside film style and narrative in order to properly analyze these texts. ${ }^{24}$ Indeed, marketing can be seen as part of the film text for Wyatt, as can the industrial structure that produces it. Promotional music videos for a film like Top Gun (1986), Wyatt argues, must be considered alongside the film itself as a valid and relevant object of study in order to properly understand the film and the music video. ${ }^{25}$ This carries an important and weighty

\footnotetext{
24 Wyatt, 20.

25 Wyatt, 45.
} 
implication about the nature of textuality that is essential to a new understanding of media franchises: for Wyatt, the object of study cannot be situated in any one text, but in context. As Harold Bloom has famously said, there are no texts, only relationships between texts. ${ }^{26}$

Intertextuality is an inherent feature of media franchises, and is therefore of central concern to this thesis. Eileen Meehan makes explicit what Wyatt only alludes to and what Jenkins discusses as a facet of convergence in the 1991 article "Holy Commodity Fetish, Batman!" Coining the phrase "commercial intertext" to refer to Batman (1989) and the larger Batman franchise, she underscores the importance of intertextual relationships in the production and marketing of Hollywood blockbuster films. Positioning the Batman film as her "major text" within a web of other texts, products and cultural memories, she suggests that the film brings about a particularly rich and complex intertext. ${ }^{27}$ In her words:

This web of cross references creates an intertext into which we fit ourselves, positioning ourselves to construct different readings of the film and positioning the film and its intertext to suit our own particular purposes. ${ }^{28}$

The idea of the intertext is particularly relevant to the study of franchises, which exist between many different users and readings. In order to properly understand a franchise, we must consider the multiplicity of meanings inherent to any intertextual object. Like Wasko, Meehan is concerned with political economy, and although she goes further in making clear that this approach should exist alongside discussions of intertextuality and

26 Harold Bloom, A Map of Misreading (New York: Oxford University Press, 1975), 3.

27 Eileen Meehan, "Holy Commodity Fetish, Batman! The political economy of the commercial intertext," in Hollywood: Critical Concepts in Media and Cultural Studies, ed. Thomas Schatz (New York: Routledge, 2004), 312-313.

28 Meehan, 313. 
audience reception, she continues to privilege the industrial aspect of franchises for the bulk of her article. Meehan maintains that, because Hollywood films and other forms of mainstream entertainment begin as products within a business structure, their status as commodities permeates all other facets of the intertext. ${ }^{29}$ However, as Meehan herself suggests, there are as many different readings and uses of a franchise text or product as there are audience members, critics and producers, and these meanings can exist quite apart from the commercial meanings of a franchise, and I would argue this necessitates a broader approach. Taking up her case study of the Batman franchise, consider artist Mark Chamberlain's 2005 exhibition, Queer Batman Returns, which features Batman and Robin in a variety of graphically explicit homosexual situations. ${ }^{30} \mathrm{I}$ contend that this exhibit, along with countless other apocryphal interpretations of Batman are as important a part of the franchise as is Tim Burton's Batman film, and are similarly positioned within the web of meaning we refer to as the Batman franchise. In order to effectively study media franchises, therefore, it is necessary to decentralize our approach, and look beyond economics and the perceived dominance of "major texts" to the wider discursive landscape.

Also concerned with the intertextuality of a major franchise, in this case the James Bond franchise, Tony Bennett and Janet Woollacott are adamant that it is impossible to examine a cultural phenomenon such as a media franchise based exclusively on the texts contained within. This attempt to "stabilize" texts as fixed objects of analysis is incompatible with their nature as part of an intertextual network. Instead, Bennett and

\section{Meehan, 314.}

30 Kathleen Cullen Fine Arts, "Mark Chamberlain (American 1967)," http:/www.artnet.com/Galleries/Artists_detail.asp?G =\&gid =423822183\&which $=\&$ aid $=424157172$. 
Woollacott suggest that texts are "sites around which $[. .$.$] the struggle for the production$ of meaning is conducted." 31 As noted above, the many different versions of a franchise that exist via many different readings are heavily dependant on context, and no one of these versions is more valid or "major" than another. Bennett and Woollacott go on to argue that the text itself has essentially no meaning, and, echoing Bloom, effectively does not exist except in its relationships to other parts of the intertextual network, and to the reader: all three are created and defined in the process of reading. ${ }^{32}$ Franchises, therefore, represent an ongoing and fluid process of meaning-making, and not a sequential series of texts and fixed meanings. Non-textual, ephemeral aspects such as marketing and merchandising, in this assessment, become an essential part of this same process, rather than separate objects orbiting the "major texts" of the franchise, and this idea is absolutely fundamental to my critical redefinition of media franchises. The question remains, however, how are we to study franchises in the face of such overwhelming complexity?

Toby Miller's tongue-in-cheek but powerful diatribe against the idiosyncrasies and irrelevancies of modern film studies, "Cinema studies doesn't matter; or, I know what you did last semester," further conveys the problematic complexity of examining popular culture, but also offers some useful ideas for working through these methodological problems. In order to demonstrate the sheer range of factors that must be considered when discussing Hollywood film texts, Miller, like Bennett and Woollacott cites examples related to the James Bond franchise. ${ }^{33}$ In order to fully understand the meaning

31 Tony Bennett and Janet Woollacott, "Texts and Their Readings," in The Film Cultures Reader, ed. Graeme Turner (New York: Routledge, 2002), 14.

32 Bennett and Woollacott, 16.

33 It seems that the James Bond franchise is particularly useful for considering textuality and discursivity, 
of a Bond film, Miller argues, it is necessary to consider such disparate aspects of the franchise as James Bond-themed vacation packages, auctions of Bond memorabilia, and "secret agent kit" prizes in magazine contests. ${ }^{34}$ It is not enough simply to acknowledge the dense intertextual network, however, and Miller insists that in order to properly study popular texts and culture, analyses must be narrowly contextualized both historically and socioculturally.

The life of any popular or praised film is a passage across space and time, a life remade again and again by institutions, discourses, and practices of distribution and reception that make each uptake of a text into a specific occasion. [My emphasis.] $]^{35}$

The "occasionality" of all things, Miller suggests, is vital to film and media studies, and "the division between the analysis of text and context must be broken up."36 I would extend Miller's argument beyond specific individual films to media franchises and similar discursive constructs, the lives of which are even more convoluted and shifting. To study media franchises, therefore, is to examine a particular aspect of a franchise, at a particular moment in time, in a particular place, in context of the larger intertextual network of which it is a part.

Following Miller's Bond examples, one cannot simply study Tomorrow Never Dies (1997); rather, a vast range of contextual information could come into play, depending on the focus of the study. Are we examining the film in its contemporary context, at the original period of theatrical release, or retroactively in context of its

\footnotetext{
perhaps due to its broad cultural and historical scope.

34 Toby Miller, "Cinema studies doesn't matter; or, I know what you did last semester," in Key Frames: Popular Cinema and Cultural Studies, ed. Matthew Tinkom and Amy Villarejo (New York: Routledge, 2001), 307-308.

35 Miller, 306.

36 Miller, 306.
} 
subsequent release across multiple other media platforms, and the release of several other new Bond films? Are we studying Tomorrow Never Dies in relation to its American audiences, or to its British audiences? Are we principally concerned with the film itself, or with the video game of the same name (or the novelization, or the action figures, etc.)? What about online fan fiction featuring characters from popular anime, narratively unrelated to the film but set to Sheryl Crow's theme song from Tomorrow Never Dies ${ }^{37}$ The necessary occasionality of all texts and meanings is an essential component to any account of media franchises, but creates a daunting array of factors to consider, especially when confronted with long-running and transmedial franchises such as James Bond. Evidently, no single study could truly capture all facets of a single franchise (or even of a single franchise film). It thus becomes necessary to clearly delineate the object of study as a specific occasional moment or aspect of a franchise - a specific instance - while still acknowledging the larger context that defines and informs each instance. An interesting project, therefore, could be to examine how the immense popularity of the Nintendo 64 video game GoldenEye 007 (1997, based on the 1995 film of the same name) affected the release of Tommorow Never Dies in North America only four months later. Switching the locale to Japan (where the game was released several days earlier) would create a completely different occasion and instance of the franchise, and a different project entirely. Miller's notion of occasionality, therefore, is a useful concept for accurately describing the nature of media franchises, and in developing practical methodologies for research into these complex networks.

37 Daryn Maxwell, "Tomorrow Never Dies," http://www.fanfiction.net/s/699242/1/Tomorrow_Never_Dies. 
Moving away from scholars dealing directly with franchise media, one of the most closely related fields of study is genre. On the most basic level, franchises resemble genres - in the sense that they represent the grouping of media according to some commonly held criteria. Current thinking on genre, therefore, is supremely relevant to the discussion of franchises. Rick Altman's work (particularly on the Hollywood musical) is considered seminal in the field, but his 1999 book, Film/Genre, is especially useful in its conception of genre as a semantic/syntactic/pragmatic discourse. ${ }^{38}$ Like Miller, Altman insists that we escape the "tyranny of the text" found in most traditional approaches to film studies, in which the film text is considered to be the primary object of inquiry and the central axis of all other forms and meanings in any network. ${ }^{39}$ In the study of genre, as with media franchises, this text-centric approach simply cannot be sustained. Altman instead suggests that genre is a discursive process that includes forms (syntactics), meanings (semantics) and the many different uses of those forms and meanings (pragmatics). ${ }^{40}$ The pragmatic aspect of genre, Altman argues, has not been sufficiently recognized in traditional genre studies, limiting its historical and theoretical usefulness by assuming a homogeneous understanding of a genre's function. ${ }^{41}$ Like genres, franchises "serve diverse groups diversely," and are composed of a wide variety of elements, interpretations and uses in a shifting, decentralized web of discourses vastly more complicated that the traditional text/audience dichotomy ${ }^{42}$ For the industry, franchises (like genres) are a way of linking, branding and selling various products; for regular

\footnotetext{
Rick Altman, Film/Genre (London, England: British Film Institute, 1999), 207.

Altman, 213.

Altman, 54, 100.

Altman, 207.

Altman 207, 15.
} 
audiences, franchises (like genres) represent a specific group of familiar features and characteristics according to which a film or product can be judged; for creators, franchises (like genres) are parameters for creation; for journalists and critics, franchises (like genres) carry with them a certain set of qualitative and quantitative assumptions; for some fans, franchises (like genres), are simply a mark of quality and desirability — for others, franchises (like genres) can represent an imaginary world with which to engage creatively; and so on.

These diverse and contrasting examples are only a fraction of the possible uses of media franchises. For Altman, this necessitates paying close attention to the multiplicity and discursivity of genre, and thus franchises, because any given franchise is a site of "struggle and cooperation among multiple users," constituted by a host of discourses, each working to define the imagined whole. ${ }^{43}$ Altman's ideas, and particularly his emphasis on discourse, are absolutely essential to my own research, but other contemporary theorists have pursued similar avenues of inquiry into the concept of genre and come to similar conclusions. Steve Neale, like Altman, has reassessed his own $1980 \mathrm{~s}$ approach to genre and recognizes that the concept cannot be fixed, but rather is fluid and ever-changing depending on context and use. ${ }^{44}$ James Naremore's book on film noir, More Than Night, posits that the forever contentious but always compelling genre/cycle/stylistic tendency is best understood as an idea that circulates in many different contexts for many different reasons. ${ }^{45}$ Like Altman, Naremore sees networks of meaning in terms of their fundamental discursivity. Naremore draws an analogy with

43 Altman, 208.

44 Steve Neale, Genre and Hollywood (New York: Routledge, 2000), 28.

45 James Naremore, More Than Night: Film Noir In Its Contexts (Updated and Expanded) (Berkeley, California: University of California Press, 2008), 9. 
Michel Foucault's "author function," a system of textual classification that is used, appropriated and circulated in various ways, suggesting that genres function in much the same way. ${ }^{46}$ In this sense, as Altman points out, genres (and, I would argue, to an even greater degree, franchises) can be assessed in terms of Benedict Anderson's notion of nation as an imagined community - a diverse community of franchise or genre users are part of an imagined network of texts and meanings, and are constantly engaged in the process of its definition - and it is only in these imagined relationships that nations, genres and franchises really exist. ${ }^{47}$ It is not productive, therefore, to assume that these concepts exist "out there" and to think of them as stable objects of study as some genre theorists have done in the past. ${ }^{48}$ It follows that to simply study genres and franchises as series of texts, attempting to establish objective, pseudo-scientific taxonomies of their features, would be to locate the genre or franchise at a single point with a fixed meaning, and to ignore a vast range of other relevant discourses. ${ }^{49}$ For scholars, rather, franchises (like genres) must be conceived as a framework for understanding certain kinds of discourse.

The usefulness of contemporary genre theory for the discussion of analogous concepts has not gone unnoticed. As Altman indicates in his conclusion, his semantic/syntactic/pragmatic approach can be applied to virtually any group of texts. ${ }^{50}$ Constantine Verevis, in his studies of film sequels and remakes, has presented what is another important forerunner to my own critical redefinition of media franchises. In

\footnotetext{
46 Naremore, 11.

47 Altman, 205-206.

48 Altman, 11.

49 Altman, 12.

50 Altman, 215.
} 
particular, Verevis' book Film Remakes also combines genre theory and current thinking on intertextuality to create a concise but highly effective approach to remakes and intertextual references between films. Verevis suggests that remakes are a form of institutionalized, intertextual repetition of ideas and concepts, which has industrial, textual and discursive aspects. ${ }^{51}$ Like Altman, Verevis strongly opposes text-centric approaches, and advocates a more integrated and balanced model that accounts for context and discourse as much as for form when analyzing the meaning of remakes. Traditionally, remakes are examined in relation to the perceived essential elements of the "original," which leads to simplistic taxonomies rather than meaningful analysis. ${ }^{52}$ Media franchises are also often boiled down to what are perceived to be their essential elements or features, as represented by the "official" canon, but this limits our understanding by overshadowing the (sometimes drastic) incoherences and divergences between instances of a franchise. For example, Peter Coogan, in discussing Hulk (2003) in relation to the larger Incredible Hulk superhero franchise, suggests that it is a "failed vision" of the franchise because of its particular variation on the Hulk's origin story ${ }^{53}$ Coogan assumes that there is a singular, essential and most-true canonical version of Hulk according to which all other texts within the Hulk franchise are measured, conflating his own personal opinions about Hulk with academic observation. This sort of essentialism, although common among audiences and fans, is incompatible with the academic study of franchises and remakes, the meanings of which are fluid and intertextual, not fixed. Verevis, by complicating these assumptions, situates the meaning of remakes in a

51 Constantine Verevis, Film Remakes (New York: Palgrave Macmillan, 2005) 2.

52 Verevis, 11.

53 Peter Coogan, Superhero: The Secret Origin of a Genre (Austin, Texas: MonkeyBrain Books, 2006 ), 11. 
complex network according to various uses (or rather, he refuses to situate meaning permanently at any one point). Franchises, like genres and remakes, are used to categorize and order films in a wide variety of different ways according to a wide variety of different criteria, in different historical contexts (and thus different intertextual contexts), for different purposes by different groups of users. ${ }^{54}$ The conceptual similarity between remakes and media franchises only further calcifies the importance of Verevis' work to this thesis.

As should be indicated by this brief survey, there is a wide variety of scholarship from a range of fields that is relevant to the study of media franchises, in spite of the relatively limited work directly concerned with the concept. Key writings on fandom, the entertainment industry, texts, intertextuality, genre and discourse presage the critical rehabilitation of media franchises as a concept. In particular, the multifaceted theories of meaning advanced by many of these works inform my own theory, and universally suggest a complexity of meaning-making that escapes many traditional theoretical approaches. The networks through which meaning is created are acknowledged by these authors to be more important than texts - even to the point of questioning the very existence of texts, save as constructs of the discursive web that defines them. Based upon this underlying theory, I propose a new way of understanding and studying media franchises.

What, then are franchises? Media franchises are intertextual, transmedial networks of discourse, that are used variously by various users to categorize texts and 54 Verevis, 25. 
meanings based on perceived associations between them and commonly held features, like genres. Franchises cannot be situated at any single fixed point, but are fields of meaning-making — each aspect of a franchise is discursively defined according to its relationships to other aspects. Franchises are extremely context-sensitive, and can have many different meanings depending on the context and occasionality of a given instance: franchises are not limited to "official" or canonical versions, and also include a wide range of "unofficial" apocryphal and ephemeral discourses. Many different versions of a franchise, established by different users according to different criteria in different contexts, and these versions are often inconsistent, incompatible and even incoherent with other versions. For the purposes of academic inquiry, the franchise as a whole must be seen to include all possible versions and discourses, and all versions must be considered equally valid and meaningful; different parts are used at different times, in different places, by different people, for different purposes and therefore mean different things.

How, then, do we study and understand the meaning of media franchises? As indicated above, the meaning of media franchises is highly variable depending on context and use, so the key research question must be what does this aspect of this franchise mean, in this context, at this time, to this user or group of users? This template is useful, for it allows us to closely specify the occasion with which we are concerned, rather than making the kinds of overgeneralized statements that Miller condemns. ${ }^{55}$ Additionally, by focusing our research, we can more accurately trace the discursive relationships that create meaning in franchises, effectively analyzing a specific instance without having to

55 Miller, 306. 
contend with the daunting whole. In some cases, this may be an impossible task:

instances may be difficult to research due to lack of materials and information, and others will simply be too complex or specific in their occasionality to produce any meaningful analysis. However, such instances can at least be understood in a broad sense to be part of a web of discourse, and their meaning situated within that network.

According to this model, although it is certainly possible and useful to consider canonical, "primary" fictional texts such as films and novels as objects of study, it is by no means necessary or essential. A toy Spider-Man, I would argue, is potentially as relevant and important as a film or comic book in the discursive web of the Spider-Man franchise, and can yield equal insight into the meaning of the franchise in certain contexts. By the same token, popular debates surrounding Daniel Craig's blondeness as James Bond and fan-created Pokémon costumes are as valid and meaningful a part of the network as any other franchise element, and such activity must be seen as engagement with the discursive construct we call a franchise. Representing a way of understanding and conceptualizing franchises rather than prescribing a specific avenue of inquiry, this approach is very much consistent with other critical paradigms: to return to the example of a Spider-Man toy, genre, nation, the representation of masculinity, the cultural meaning of action figures, the political economy of toy production and the historical development of superhero merchandise could all be considered. Media franchises, like any object of study, can be viewed through all manner of critical lens. It is important, however, to understand how franchises work, in all their complexity, as elaborate discursive networks of meaning. Users can range from corporate institutions to specific 
individuals, and are not limited by copyright or license. Popular notions of canon, continuity, "official" and "unofficial" versions of the franchise must be completely broken down in order to properly understand franchises as a concept, while still recognized to be important discursive constructs. The incoherence created by multiple instances within a franchise should not be decried, but rather acknowledged and studied as a basic feature of franchise networks. Drawing upon this conceptualization as a critical tool, the study of media franchises can be as diverse as the study of media itself.

Throughout this chapter, I have argued that the media franchise, which ostensibly originates as an industrial, economic concept, has come to be deployed by a much wider variety of users, beyond the industry and including fans and consumers. Engagement with franchise media is structured by the concept of franchises: as Jenkins suggests, audiences are invited and encouraged to interact with franchises in certain ways. ${ }^{56}$ And yet, in that engagement the concept of franchise itself has been restructured and understood in many different ways, in many different contexts. Franchises, therefore, can be seen as the site of a complex interaction between various groups of users, rather than as a fixed economic structure. In Chapter Two, I will consider how the industry and fans attempt to impose order on and maintain control over franchise discourse.

56 Jenkins, 96. 


\section{CHAPTER TWO:}

\section{THE “OFFICIAL” VERSION — DOMINANT FRANCHISE DISCOURSE}

If, as I have argued, media franchises are networks composed of a wide variety of texts, products and discursive activity, the dominant discourse among fans and in the industry is surely one of canonicity and continuity. ${ }^{57}$ Franchises, like genres and other analogous ideas, are primarily a mode of distinction, a way of ordering and categorizing meanings according to various criteria. For users of a franchise, these criteria serve primarily to distinguish between what is and is not a valid part of a franchise, and in doing so establish a coherent map. The entertainment industry in particular is concerned with this process of ordering (whether explicitly or implicitly), and usually attempts to maintain and control an "official" version of the franchise in order to effectively brand and market it. In some cases this version is referred to as the canon of a franchise, and for many users this canon represents the "true" franchise, although it can change dramatically over time. For my purposes, the term canon will indicate the various "official" versions of a franchise discursively created by the industry and fans, rather than any one singular version. Within the discourse of canonicity, another major concern is continuity: the question of chronology and consistency throughout the fictional universe of a franchise (what Jenkins refers to as a storyworld). In large franchise networks, especially those with a rich internal mythology, continuity is used to maintain order in the face of overwhelming complexity. In some cases, as in superhero franchises, multiple

57 This notion is based partially on conversations between Nick Nguyen and Bart Beaty, related to me by Nguyen. 
parallel continuities must be established simultaneously - consider, for example, the many parallel versions of Spider-Man. Continuity is used to establish what aspects, features and elements are "official" and thus legitimate, and to maintain coherence across multiple franchise texts. If a text is out of continuity, is is generally considered noncanonical; canonical, fictional texts are elevated as the most important parts of a franchise, with non-canonical, non-fictional and non-textual elements relegated to the margins of a franchise as apocryphal or ephemeral.

How does franchise canonicity and continuity function within a larger network that extends far beyond those dominant discourses? What aspects of a franchise are considered canonical by different groups of users in different contexts, and what is the relationship between these canons? In this chapter, I will analyze industry and fan approaches to canon and continuity, and the complex and sometimes contentious interaction between between the two. As I have already argued, along with the complexity and expansive size of franchise networks comes narrative, thematic and semantic incoherence. Differing discursive versions of the franchise compete and interact, each attempting to define and order the whole but in fact producing new incoherences by creating further conflicting versions. Questions of occasionality and context only further exacerbate this incoherence. Even in a smaller franchise, a wide variety of discursive versions circulate, and larger, older and broader franchises like Spider-Man or Sherlock Holmes contain many different canons and continuities. Just as canon is understood in contemporary Biblical criticism, ${ }^{58} \mathrm{I}$ contend that these discursive

58 Christine Helmer and Christof Landmesser, "Introduction: A New Biblical-Theological Approach to the Unity of the Canon," in One Scripture or Many? Canon from Biblical, Theological, and Philosophical Perspectives, ed. Christine Helmer and Christof Landmesser (New York: Oxford University Press, 2004) 2-3. 
processes of ordering and definition are not fixed meanings, but can be seen as an attempt to map an illusory coherence and logic onto the overwhelming incoherence that characterizes media franchises. This does not render notions of franchise canon invalid or meaningless - rather, for our purposes, such concepts must be situated within the franchise network among many other valid discourses, all of which are engaged in the same fundamental process of organization and meaning-making. The discourse of canonicity itself is an important aspect of franchise study, but cannot be treated as the most or only important aspect.

Elsewhere, I have suggested that the entertainment industry's approach to media franchises is by and large composed of strategies of reintroduction: each new fictional text added to a franchise network represents a reintroduction (whether a reaffirmation or a reassessment) of what the industry perceives to be the familiar and desirable aspects of the franchise. A balance between novelty and nostalgia is thus essential to successful reintroduction within any franchise, although this balance may be established in many different specific ways. For the industry, there is a distinct hierarchy in which narrative texts are seen as dominant within the network, while merchandise and other licensed materials, in spite of their central importance to the industry's profits, are considered peripheral rather than as meaningful parts of the franchise. Strategies of reintroduction, though many and varied, always function discursively to present a coherent and consistent vision of the franchise, that often involves distancing a text from certain parts of the franchise as much as aligning it with others. These strategies are fundamentally 
based upon the new iteration's relationships to the larger, existing discursive network, and are designed to position it within that network. In addition to fictional texts, promotional rhetoric and other extratextual discourses are also constructed according to the strategy of reintroduction being employed, as we will see in Chapter Four. In this section, I will outline three common strategies of reintroduction drawing examples primarily from superhero franchises: alignment, the concept of retroactive continuity (popularly known as retconning), and distancing (in extreme cases referred to as rebooting). These are by no means distinct categories (indeed, I will argue that most franchise texts combine aspects of all three), nor do they represent a comprehensive taxonomy of reintroduction strategies (for the industry is constantly conceiving of new strategies). Nevertheless, these analyses will serve as indicative examples of how the entertainment industry attempts to create order, maintain canon and control continuity in various media franchises, while unwittingly serving to intensify the very incoherence they are designed to combat. Perhaps the most common approach for the industry when presenting new franchise media is to align the new product as directly as possible with some part of the pre-existing franchise - in effect attempting to create a direct line of inheritance through the development of the franchise. In some cases, this is relatively straightforward: it seems natural enough for a new film in the Jason Bourne franchise to be narratively, stylistically and thematically linked to the previous Bourne film. But what of the Bourne novels? What is the relationship between The Bourne Ultimatum (2007) and the novel of the same name? Additionally, the video game The Bourne Conspiracy (2008) recreates various scenes from the film series, but does not feature Matt Damon's likeness for the 
main character. How does this affect its canonicity? Even in a seemingly simple franchise we have three different lines of continuity potentially overlapping and interacting.

Although industry rhetoric seeks to keep these lines distinct by avoiding direct alignment, the commercial impetus of the industry nevertheless complicates this distinction by crossmarketing the various lines with common branding and imagery. As indicated above, the strategy of alignment does little to alleviate the incoherence of a franchise, and in some cases can prove to be even more confounding than other strategies. ${ }^{59}$

Superman Returns (2006) is a recent example of the strategy of alignment that, because it attempts to align itself with films released more than twenty years ago, offers us the opportunity to analyze a particularly pronounced instance of the strategy. As has been already alluded to, superhero franchises almost invariably constitute uniquely convoluted and incoherent discursive networks, and the most recent Superman film is situated carefully within this complex. Specifically, Superman Returns is positioned by its creators as a more-or-less direct sequel to the first two Superman films, Superman: The Movie (1978) and Superman II (1980), starring Christopher Reeve. ${ }^{60}$ Immediately, this alignment creates a significant problem of continuity - what of the now-disowned Superman III (1983) and Superman IV: The Quest for Peace (1987), which before now were considered direct and canonical sequels to Superman II? The strategy of alignment

59 I have colloquially referred to "second-movie syndrome," in which sequels to popular franchise films over-zealously attempt to create continuity and familiarity, stretching even the limits of Hollywood blockbuster plausibility by linking every character, plot point and situation to the previous film. Particularly notorious examples include Magnum Force (1973), Die Hard 2 (1990) and Pirates of the Caribbean: Dead Man's Chest (2006). (In fairness to Die Hard 2, franchise protagonist John McClane himself self-reflexively comments on the film's absurdity: "How can the same shit happen to the same guy twice?")

60 Heather Newgen, Superhero Hype!, "Superman Returns Screenwriters Dougherty and Harris," http://www.superherohype. com/news/supermannews.php?id=4393. 
in Superman Returns, rather than simply extending an existing line of continuity, creates a new one. There now exist two "official" versions of the modern Superman film series: one comprising Superman, Superman II and Superman Returns, the other comprising the "original" canon of the four Reeve films. As noted above, the commercial impetus of the industry furthers this duality, as DVD boxed sets combining both continuities exist.

The temporal distance between Superman Returns and the other films in this newly formed canon seems to necessitate the fulfillment of an important generic function of superhero stories - the origin story. ${ }^{61}$ Because it is intended to align with Superman II rather than present a completely new version of the franchise, however, Superman Returns does not simply retell Superman's origins - these origins, after all, have already been depicted in Superman: The Movie. Instead, Superman's absence and return within the film's fictional narrative (in addition to analogizing his lengthy absence from realworld screens) allows the film to create a partial recap of the earlier origins story, to deliberately parallel certain sequences from Superman: The Movie, and to present a new flashback to Superman's youth that fits ostensibly into the newly established continuity.

At the beginning of Superman Returns, we are shown the planet Krypton prior to its destruction, looking very much as it did in the $1978 \mathrm{film}$, albeit with a new veneer of digital polish. The first spoken lines in the film are a voice-over by Marlon Brando as Superman's father, Jor-El, taken from footage shot by Richard Donner for the first two Superman films. In many ways this is the most overt means by which Superman Returns is aligned with the rest of the franchise. Brando's voice-over is used several times,

61 Brian Fried, "Radioactive Kryptonite: The Industrial Factors Behind the Use of Origin Tales in ComicsBased Films," (MA Thesis, Carleton University, 2001), 88-89. 
maintaining this nostalgic alignment throughout the film, rather than acknowledging this "past" in the beginning before moving gradually away from the older films. Following the brief speech, with an orchestral swell we witness the destruction of Krypton and baby Kal-El's asteroid-like escape pod - the one moment of the previous films that is repeated in the new film - re-rendered in spectacular CGI. The combination of Brando's repurposed speech with the new version of Krypton's end encapsulates the film's strategy of reintroduction: this is simultaneously the nostalgic Superman of the previous films, and a stunning modern iteration of the hero. The opening titles sequence that follows replicates the opening credits of Superman: The Movie, with similar bright blue text shooting onto the screen while the camera soars through space.

The next element in Superman Returns' pseudo-origins story comes a bit later in the film, and parallels one of the most famous moments of Superman's traditional origin. As Martha Kent, Superman's adoptive human mother, quietly does the dishes, the earth begins to shake, and what appears to be an asteroid crashes into the wheat fields - very much like the traditional crash-landing of baby Kal-El's escape pod. This sequence is ambiguous enough at first that it could easily be misconstrued as being a retelling of Superman's first arrival on Earth. But, as Martha inspects the wreckage, it becomes apparent that this is a full-grown Superman's arrival "home." It seems that over the course of the opening credits, we have been transported not only though space, but through time to the fictional present - a subtle but effective way of further aligning the film with its predecessors. Superman is naked and disoriented, much like a child, and the scene ends with Martha cradling her alien son in her arms. Like the pre-credits sequence, 
the scene combines familiarity with novelty and creates narrative and thematic continuity by alluding to "past" events.

Subsequently, the film presents a flashback to Clark Kent as a boy enjoying and discovering his superhuman powers (framed as the adult Superman's own reminiscence, again stressing continuity). Where Superman: The Movie introduced audiences to a high school senior-aged Clark who is fully aware of his powers (and is frustrated that he cannot show them off to his friends and rivals), Superman Returns depicts a younger Clark, ostensibly filling in the blanks in Superman's filmic childhood and further situating the film in relation to the franchise canon. Clark is shown first running at blinding speed through cornfields, but the scene quickly shifts its focus to powers that Superman: The Movie did not depict in its high school scenes. The sequence has Clark seemingly aware of his ability to jump incredible distances, but not yet of his ability to fly. As Clark leaps high into the sky and tumbles accidentally through the roof of his father's barn, he shields his face from the impact - which never comes. The boy is suspended in air, apparently able to levitate, and the scene ends. In choosing to insert this particular moment into Superman's canonical past, the film effectively conveys the sense of an origin story without actually re-depicting this version's already-established origins. The flashback is presented as fully in continuity with the other films, as one of the many hitherto-undocumented events in Superman's youth, in order to calcify Superman Returns as a legitimate and direct successor to the canon while still presenting audiences with something new and exciting.

Other ways in which Superman Returns textually aligns itself with the canon 
include the musical score based on John Williams' original Superman themes, the casting of Brandon Routh (who somewhat resembles Christopher Reeve), allusions to Superman and Lois Lane's prior relationship, and the maniacal plan of Lex Luthor to gain control of valuable new real estate by destroying an entire American coast, which parallels the character's scheme in Superman: The Movie. These references to earlier films link the new instance of Superman closely to its predecessors. However, the film is also informed by other, non-cinematic, parts of the franchise, such as the notorious "Death and Return of Superman" comic book storyline, which more broadly aligns Superman Returns with canonical elements of the larger franchise and its mythology. A visual allusion to the cover of the first Superman comic book in one scene similarly situates the film in relation to the franchise canon. Other aspects of Superman Returns, however, are designed to modernize the character and bring the franchise into the $21^{\text {st }}$ century. The cut of Superman's costume, for example, is considerably more svelte that Reeve's 1940s wrestler-style outfit, and feminizes the hero's appearance in keeping with contemporary fashion trends. Other changes include the potency of some of Superman's powers and the inconsistent ages of various characters in the film. These aspects diverge significantly with the films Superman Returns is intended to align with, and contribute to the general incoherence of the franchise. I raise these issues of continuity not to criticize the film (although many fans take issue with some or all of these examples), but to demonstrate how the strategy of alignment invariably is balanced with attempts at novelty and freshness in hopes of success with audiences.

As I have argued throughout this thesis, the study of franchises must not be not 
limited to traditional textual analyses. The marketing, merchandise and other promotional materials for Superman Returns are equally representative of and governed by similar strategies of reintroduction. In particular, the print and poster campaign for the film stresses a nostalgic connection to the earlier Superman films, as well as to the franchise as a whole, by maintaining the bright, primary-colours palette often associated with Superman. Early teaser posters for the film simply feature the familiar Superman logo and the text "Returns 2006." By relying entirely on the ubiquitous familiarity of the logo, the poster makes a bold statement, firmly positioning the new film as an authoritative version of the hero by foregrounding the nostalgic iconography of the franchise. Other promotional rhetoric for the film draws on this nostalgia, but also emphasizes the excitement of a new take on Superman. The DVD liner notes, for example, begin by simply declaring that "HE'S BACK." Later, however, the blurb suggests that director "Bryan Singer (X-Men, X2) gives the world the Superman it needs, honouring the legend everyone loves while taking it in a powerful new direction," concisely encapsulating the strategy of reintroduction governing this instance of Superman. Similarly, the promotional website for the DVD release begins with a quote from Jor-El, Superman's birth father, as played by Marlon Brando, but later refers to Singer's "extraordinary new vision that showcases groundbreaking visual effects technology." ${ }^{962}$ Here, again, the marketing rhetoric clearly demonstrates the industrial approach to franchise canon, endeavouring to balance familiarity with novelty.

Essentially, the strategy of alignment described above is an attempt to navigate a complex and incoherent network of meanings and to make sense of it by mapping onto it 62 "Superman Returns," http://supermanreturns.warnerbros.com/. 
an overarching continuity or logic. However, as illustrated by the example of Superman Returns, the strategy invariably necessitates the imposition and omission of various aspects of the existing franchise for the sake of continuity and audience appeal, ultimately resulting in still more incoherent versions of the franchise. The process of retroactively creating continuity - commonly known in comic book culture as "retconning" - is an extreme example of this strategy, and refers to instances of re-writing or re-framing the fictional history of a franchise in order to account for and thus incorporate such incoherences into a single continuity. In Superman Returns, the death of Martha Kent is retconned via the omission of Superman $I I I$ and $I V$ from the new continuity, allowing her to appear in the new film very much alive. ${ }^{63}$ Jason Dittmer discusses a particularly elaborate instance of retconning in his article "Retconning America: Captain America in the Wake of WWII and the McCarthy Hearings. ${ }^{364}$ In order to account for the McCarthyinfluenced, anti-Communist and racist 1950s version of Captain America in the more liberal 1960 s, it was retroactively determined that this version of the hero was in fact an overzealous Captain America impostor, and that the "real" Captain America (the Nazismashing 1940 s version) was in fact frozen in the North Atlantic, only to be retrieved and resuscitated by The Avengers in the 1960s. This "real" version of the hero would go on to fight and defeat the corrupt and misguided 1950s impostor, which ostensibly aligns four decades of comics and three otherwise distinct versions of Captain America into one consistent continuity (and, as Dittmer points out, effectively exonerates America-as-

63 Another well-known example of retconning would be the infamous "it was all a dream" negation of the entire 1985-1986 season of Dallas, proving that the dominant discourse of continuity is not at all limited to geek culture.

${ }^{64}$ Jason Dittmer, "Retconning America: Captain America in the Wake of WWII and the McCarthy Hearings," in The Amazing Transforming Superhero! ed. Terrence R. Wandtke (Jefferson, North Carolina: McFarland \& Company, 2007). 
represented-by-Captain-America for the ideologically conservative 1950 s during the liberal-leaning 1960s and 1970s). ${ }^{65}$ However, as I have already argued, this "official" version of the Captain America franchise does not supplant the previous existence of an "official" racist Captain America, and effectively creates three equally valid discursive versions of the hero - the new "official" version as well as the two formerly "official" versions (not to mention the versions featured in film serials, novelizations, The Kinks' references to the hero in the song "Catch Me Now I'm Falling," and so on). Although retroactive continuity allows the industry to present a seemingly coherent franchise, closer examination invariably reveals that the practice is largely illusory. This is not to suggest that retconning is bad or somehow inauthentic (as some fans do), but rather to demonstrate how for both the industry and for fans, the franchise is constructed and experienced not through any fixed textual meaning, but through these discourses.

For the industry, success or failure of a franchise product (narrative or otherwise) is measured in terms of profits. If products perform poorly or receive negative audience reactions, as in other industries the brand must be either ended or somehow rehabilitated. For example, after five films, twelve novels, one video game and a pinball machine, the Dirty Harry franchise petered out in the wake of the poor performance of The Dead Pool (1988). This does not, obviously, constitute a complete abandonment of the franchise: new DVD and Blu-Ray editions, not to mention television airings and licensed merchandise allow the franchise owners to continue capitalizing on the Dirty Harry brand. However, the "official" version of the Dirty Harry franchise is considered over, so far as the industry is concerned - as opposed to an active franchise. The strategy of

65 Dittmer, 41-42. 
alignment can still be effective in situations like this: Die Hard, Terminator, Indiana Jones and Rambo are all examples of franchises that have been more-or-less successfully reintroduced, in continuity, after a significant period of inactivity. ${ }^{66}$ In many other cases, however, if a franchise is valuable and popular enough to remain profitable, but has been soured by poor performance, alternative strategies of reintroduction may be employed. If the strategy of alignment seeks primarily to link the new version of a franchise to earlier canonical versions, the distancing strategy seeks to disassociate the new version from unpopular or failed versions. ${ }^{67}$ One approach that has gained currency in recent years is colloquially known as "rebooting" a franchise, and involves the partial or complete reimagining of a franchise and the establishment of a new canon. In distancing the new version from other versions of the franchise, reboots often emphasize novelty and freshness in relation to less popular or failed versions, but in many cases nostalgia plays an equally important part.

A useful counterpoint to Superman Returns is Batman Begins (2005), which rebooted the Batman franchise on film in the wake of extremely negative reactions to Batman Forever (1995) and Batman and Robin (1997), and after numerous failed attempts at a fifth film in that series. Although those films were deemed unsuccessful, the franchise as a whole remained strong among fans and mainstream audiences, via comic books, TV shows and other media as well as in popular discourse. Batman Begins, therefore, firmly positions itself within the larger Batman franchise, drawing on such

${ }_{66}$ Twelve years in the case of Die Hard and Terminator, nineteen in the case of Indiana Jones, and a full twenty in the case of Rambo.

67 Superman Returns can be seen as both aligning itself with the canon and distancing itself from the less popular third and fourth film iterations, but the emphasis within the film and in marketing discourse is on the alignment rather than the distancing. 
canonized comic books as The Dark Knight Returns and Batman: Year One, but presents a stark and deliberate contrast to the colourful, campy aesthetic of the previous Batman films. One of the most important ways in which Batman Begins distances itself from those films is in its embracing of a realist aesthetic. The film depicts Batman as a moreor-less plausible character in a more-or-less realistic context, as opposed to a fantasy hero in a fantasy world. Batman's tools and gadgets, therefore, are rugged and utilitarian as opposed to ornate and stylized - the new version of the Batmobile in particular, the Tumbler, more closely resembles a military all-terrain vehicle than it does a sports car, and seems infinitely more practical. Batman's origins story is similarly re-created to include extensive training, somehow making his seemingly extraordinary physical capabilities more believable, at least in context. If Superman Returns deliberately aligns itself with earlier filmic versions of the hero, Batman Begins deliberately eschews those connections, drawing instead on a wide variety of other sources within and outside of the franchise to reintroduce Batman in a new iteration.

Posters and print ads for Batman Begins also serve to distance the film from its maligned predecessors. The campaign features sober, stark and dramatic images: a calculated far cry from the campy posters for Batman and Robin. The Batman logo, similarly, is reinvented for Batman Begins, with the familiar, smoothly rounded bat icon of the previous films replaced with a sharp, angular version. The logo is brought down to its bare essentials, appearing almost propagandistic in its gravity, and is a unifying symbol for the film's marketing campaign. Like other elements of the film, the new logo positions the film against the more campy iterations of Batman as a gritty and serious 
alternative, suggesting that the film boils the Batman franchise down to its most essential features. Copy and promotional rhetoric for the film stresses the character psychology of Bruce Wayne, and director Christopher Nolan's strict adherence to realism. ${ }^{68}$ Screenwriter David S. Goyer states, on the official website for the film:

[o]ne of Chris' mantras when we were working on the script was It has to be real, it has to be real [...] We applied that philosophy to every aspect of the story, even down to the most minute details - Why are the bat ears so tall? Why does the Batmobile look the way it does? We developed a logical explanation for everything that Bruce Wayne does and for every device he acquires in the film. ${ }^{69}$

The website also serves to align the new film with some of the canonical Batman texts from which Batman Begins is ostensibly drawing inspiration. Quotes from the original appearance of the hero in Detective Comics \#33 and from Batman: Year One situate the new film among some of the most famous versions of Batman. The website even features classic issues of Batman comics from throughout the franchise's history that relate to the film (such as an early account of Batman's origins and the first comic book appearances of Batman Begins villains R'as Al Ghul and Scarecrow), viewable online for free. Evidently, the film-makers and studio cannot explicitly disown the previous Batman films - especially considering that a boxed set of the original four films was released to coincide with and capitalize on the release of the new film - but through careful rhetorical positioning and alignment with key texts in the Batman canon, the message is implicitly clear: this version of Batman is understood to be more genuine and valid than other versions (in spite of the fact that they too have also been presented as genuine and

\footnotetext{
68 Nolan's burgeoning auteur status is also important to the marketing of Batman Begins, and became even more central to the rhetoric surrounding the film's sequel, The Dark Knight (2008).

69 "The Origins of the Black Knight," http://www2.warnerbros.com/batmanbegins/productionnotes.
} 
valid in the past).

If the strategy of alignment is a discursive process of ordering by which the industry and creators seek to draw a continuous line through the incoherence of a franchise, the distancing strategy can be seen as the attempt to organize that incoherence into an array of different parallel, isolated lines. Superman Returns and Batman Begins, therefore, represent both strategies on some level, each situating themselves within a distinct continuity (Superman Returns to the existing film series and Batman Begins as the first film in a new, rebooted series) but also distinguishing themselves from other, parallel versions within the franchise. Within each of these versions, there is an attempt to maintain internal coherence, even while multiple versions of the franchise exist, overlap and interact in complex ways. In effect, the distancing strategy attempts to ignore this incoherence, leave it behind, and start anew. Needless to say, this isolation is no less illusory a process than the continuity created by the strategy of alignment, as the new version is inevitably coloured and defined by other versions.

As indicated above, these differing strategies are not clear-cut, and most franchises do not fall neatly or consistently into either category, but instead are governed by an amalgam of approaches — the unique and complex discursive strategies according to which the James Bond franchise is constructed, for example, could never be so easily pigeonholed..$^{70}$ The sprawling Star Wars franchise for is usually presented as a single continuous narrative and contiguous universe, in spite of many, many incoherences, revisions and retcons. In fact, Lucasfilm employs Leland Chee to maintain an internal

70 Ludovic Trautman, "A Timeless Character Born Within History: The Paradox Of James Bond In The Novels And On The Screen" (paper presented at the annual Film Studies Association of Canada Graduate Colloquium, University of Alberta, Edmonton, February 13-15, 2009). 
continuity database called The Holocron. Chee has been given the task of keeping track of the canonicity of virtually all elements of the Star Wars franchise in a categories ranging from the inviolable George Lucas canon (which encompasses only the six "official" films), to completely non-canonical, in order to preserve continuity. ${ }^{71}$ This allows Lucasfilm to present a singular, apparently unproblematic storyworld and to delineate non-canonical elements as such without completely removing them from the franchise discourse. ${ }^{72}$ On the opposite end of the spectrum are comic book franchises and others that are rebooted and retconned on a regular basis and often include and acknowledge multiple "official," active versions simultaneously. For the industry, confronted with the fundamental incoherence of media franchises, strategies of reintroduction allow each instance of a franchise to be presented as "official," coherent and valid (often while invalidating or deemphasizing other instances), and to be effectively marketed. The ways in which a new franchise text is discursively positioned, aligned with certain parts of the franchise and distanced from others, is a process of definition that represents a key discourse in the production of meaning within a franchise.

Fan discourse is no less a part of this process of definition and meaning-making. As noted above, the canon represented by the industry's version of a franchise is a potent discourse, and in many cases fans will defer (or claim to defer) to this "official" version. Canon lists, chronologies and continuity notes compiled by the industry, such as The Holocron, represent for fans a seemingly fixed and stable entity, and are reiterated and

73 Chris Baker, "Meet Leland Chee, the Star Wars Franchise Continuity Cop," Wired, http://www.wired.com/entertainment/hollywood/magazine/16-09/ff starwarscanon?currentPage=all.

72 See Chapter Three for a more detailed discussion of Star Wars apocrypha. 
aggregated on fans sites like the Wookiepedia into elaborate continuous histories.

However, even within the "official" version, as we have seen, there is great incoherence and variability, for as the franchise expands, changes and is reintroduced over time the "official" discourse changes also. From this incoherence and based upon their own experiences with the franchise, fans and fan communities discursively create and circulate their own versions of a franchise, including those aspects and elements that they prefer and omitting those that they deem inconsistent or inauthentic. Indeed, the term "fanon" is sometimes used to refer to the fan canon as distinct from the "official" canon, although this notion is rejected by some, such as Leland Chee (who seems to perceive it as a threat to the "official" Lucasfilm version of Star Wars). ${ }^{73}$ Certainly, as Will Brooker demonstrates in his book Using the Force: Creativity, Community and Star Wars Fans, there is little if any agreement among fans as to what constitutes a canon.$^{74}$ These fan versions may or may not be partially or totally consistent with the "official" version, but in either case represent additional layers of complexity and incoherence within the franchise network. Furthermore, the fact that many fans seem driven to harshly question, critique and otherwise contest any new "official" version suggests that there is a more complex (and sometimes divergent) relationship between industry and fan discourses of canon and continuity than either group might care to admit. Much of fan discourse, especially among superhero fans, is based around questioning whether different texts and elements ("official" and otherwise) are "true" to the "original" meaning or features of the franchise. But what exactly constitutes truth and originality within the complex,

73 Baker.

74 Will Brooker, Using the Force: Creativity, Community and Star Wars Fans (New York: Continuum, 2002), 113. 
incoherent discursive network of a franchise? Fans adhere strictly to what they perceive to be the essential aspects and features of popular franchises, and yet there is no consensus as to what those aspects and features are. In this section, I will address the relationship between this fan discourse of canon and continuity and the "official" industry versions, citing examples from Superman and Star Wars. First, I will discuss recent fan and journalistic reactions to the possibility of a darker, post-Superman Returns filmic reboot of the Superman franchise, considering how these reactions reflect certain conceptions of Superman as a character that are potentially inconsistent with the “official" version. Shifting my focus to Star Wars, I will analyze several instances from that franchise in which fan and industry discourses overlap and interact to change and define the franchise in particularly tangible ways.

Superman Returns, while successful at the box office, has not enjoyed the same fan acclaim as Batman Begins, and although The Dark Knight has become one of the highest-grossing films of all time, there has yet to be a sequel to Superman Returns. In late 2008, rumours began to emerge that Warner Bros.' intention was to reboot the franchise in a new and darker iteration, in hopes of capturing the same success and critical acclaim as the stark and serious Batman reboot (also a Warners franchise) ${ }^{75}$ On fan-oriented websites and in fan communities, questions and concerns have arisen about the rumoured new take on Superman. Although the possibility of a reboot has largely been accepted by fans and movie news websites, the idea of a darker version of the Superman franchise has been met with considerably more resistance. Take, for example,

75 This example of the discursive relationship between sub-franchises of the larger DC franchise is in and of itself interesting - consider also the inter-franchise influence of the Batman reboot on The Incredible Hulk (2008). 
this quote from director, comic book writer, fanboy icon and erstwhile Superman movie screenwriter Kevin Smith: "if you want to take a realistic approach to him that's fine, but I don't think you can turn him into an angry character. Superman is about the hope in people, the good in people, whereas Batman is about the more driven, hungry for justice angry side of us." ${ }^{, 76}$ Fellow comic writer Jeph Loeb concisely summarizes the same argument: "Superman, the character, inspires hope, as opposed to Batman, who inspires fear."77 These arguments are both based on assumptions about the "true" nature of Superman. But Superman does not exist in any one version but in many, many different versions, and indeed some of those versions have emphasized darkness and fear rather than hope. ${ }^{78}$ More to the point, Superman, as a discursive construct, is whatever discourse and social consensus imagines him to be, and so any new version of the franchise ("official" or otherwise) is exactly as valid as any other version, except according to personal opinion. To say that Superman is not dark is really to say that one's own preferred conception of Superman is not dark. The reactions cited above, therefore, indicate a disconnection between a firmly held personal vision of Superman and the potential new version, but are phrased as though there is a fixed, permanent and true version of Superman according to which all others are measured. No such template exists. To suggest that a dark Superman is inconsistent with the nature of the franchise is, in and of itself, inconsistent with the nature of franchises generally. It is largely through this kind of discourse, however, that fans map coherence onto the complex multiplicity of

76 "Should Superman Go Dark?" http://splashpage.mtv.com/2008/08/26/should-superman-go-dark-weask-kevin-smith-jeph-loeb-and-other-comic-creators/.

77 Ibid.

78 Frank Miller's version of Superman in The Dark Knight Strikes Again, for example, positions the socalled "representation of hope" as a misguided government stooge. 
franchises: by framing diverse personal preferences and opinions as essential features. These fan versions, of course, are no less important and relevant to the larger franchise discourse, and can even impact "official" versions, as we will see in the coming paragraphs.

Fan discourse is evidently an important defining factor for popular franchises. In some cases, dissonance between fan and "official" discourses leads fans to willfully disown certain parts or aspects of the "official" versions in order to sustain a personally preferred version. For example, in response to promotional screenshots from the forthcoming Diablo III, a sequel to the wildly popular Blizzard video game Diablo II (2000), have been met with outright hostility by some fans of the franchise. ${ }^{79}$ Certain more colourful screenshots from the forthcoming game have been deemed to be inconsistent with the dark tone of its predecessors, seen to be an essential feature of the franchise. Some fans have even gone so far as to create Photoshopped "corrections" of the images, that in turn has led Blizzard to release sarcastic fake screenshots from the game featuring unicorns and a "love meter." ${ }^{"} \mathrm{It}$ has yet to be seen whether the negative reaction from some fans will hurt sales of the new game, but like the Superman example above it is obvious that the relationship between industry and fan understandings of a franchise can be contentious. In other cases, however, the impact of fan reactions (whether positive or negative) to the "official" version of a franchise becomes becomes even more tangible, with the industry responding directly by creating franchise products that reflect (and thus potentially capitalize on) fan conceptions of the franchise. These

79 http://kotaku.com/5021118/diablo-fans-petition-against-diablo-iii.

80 http://kotaku.com/5146004/now-are-you-happy-with-diablos-art-style. 
situations can be seen as exemplifying the constant circulation of often incoherent ideas and meanings that defines franchises as discursive constructs.

The Star Wars franchise is known particularly for its rabid fanbase, and for the often strained relationship between fans and the "official" creators and owners, Lucasfilm - made even more complicated by the massive volume of information included in the franchise. When Episode I: The Phantom Menace (1999) introduced the concept of midichlorians, a biological component that can be measured in Force-sensitive characters, some fans were disappointed and disillusioned by what was perceived to be an oversimplified and too-literal understanding of the formerly mystical Force. ${ }^{81}$ As a result, for many fans the Holocron-approved concept of midi-chlorians is omitted or deemphasized in their personal version of Star Wars, in favour of a mystical version of the Force seen in the earlier film trilogy and throughout much of the franchise. As a result, midi-chlorians have been deemphasized in most subsequent Star Wars media (though not retconned out of "existence"). The character of Jar Jar Binks has been similarly disowned by many fans, and has been similarly deemphasized by Lucasfilm. By the same token, many fans took issue with the prequel trilogy as a whole, and deny the entire spectrum of more recent Star Wars media in their personal versions. ${ }^{82}$ The Special Editions of the earlier Star Wars trilogy released in 1997 also created controversy among fans, due to subtle changes to certain key scenes. Rather than approach the new version of the film as an alternative version of the still-existing "original" version, fans instead tend to frame such changes as a devaluation and an affront. The "Han shot first" phenomenon, which included t-shirts,

${ }_{81}$ Biology in Science Fiction, "Star Wars and the Midi-Chlorian Menace," http://sciencefictionbiology.blogspot.com/2007/06/star-wars-and-midi-chlorian-menace.html.

82 "Expanding Our Mission," http://www.hanshootsfirst.org/mission.aspx. 
comic strips, and outside references (in Kevin Smith films and even in a wide variety of "official" Star Wars media), emerged in protest to an early scene in the Special Edition of Episode IV: A New Hope (1977/1997), which recast Han Solo's cold blooded murder of the bounty hunter Greedo as an act of self-defense..$^{83}$ The scene became in many ways symbolic of larger fan outrage against what is perceived as the violation of sacred canon texts by a tyrannical industry — in spite of the fact that, as I have argued, these texts already exist in many discursive versions. ${ }^{84}$

These fan discourses do not exist in a vacuum, and are interwoven with the "official" franchise in significant ways. No doubt partially in reaction to the "Han shot first" protests, and seeing the potential market for an "unadulterated" version of the earlier trilogy, Lucasfilm has since released the theatrical versions of those films on DVD, thus incorporating aspects of the fan discourse into the "official" version, if not the "official" canon. As Will Brooker notes in Using the Force: Creativity, Community and Star Wars Fans, the development of Boba Fett as a significant character in the Star Wars franchise has been a similarly elaborate discursive process. ${ }^{85}$ Initially appearing in animated segments of the ill-fated "Star Wars Holiday Special" (1978), and shortly thereafter as an action figure, high levels of engagement among fans with Boba Fett in the special, with the toy and later with the mysterious and brief appearance of the character in The Empire Strikes Back (1979) made Boba Fett one of the most popular characters among Star Wars fans. ${ }^{86}$ This in turn has led subsequently to the extensive expansion of Boba Fett's role within the "official" canon, both in the prequel trilogy and

83 Wookiepedia, "Han shot first," http//starwars.wikia.com/wiki/Han shot first.

84 "Han Shoots First," http://www.hanshootsfirst.org/.

85 Brooker, cited in Jenkins, 115.

86 "The Star Wars Holiday Special" is discussed in more detail in Chapter Three. 
in a wide variety of other media. Perhaps what is most interesting about this particular case is how the history, function and personality of the character vary radically, with Boba Fett shifting from a sadistic but generic (and often decidedly inept) villain in earlier Star Wars media, to a fully-developed anti-hero and nemesis to Han Solo in Star Wars novels and comics of the 1980 s and1990s, only to be sutured into the prequel trilogy, complete with a new canonical backstory, an explanation of his skills and unique armour, and a pathos of vengeance. As noted above, each of the many instances of Boba Fett have existed as canon in various specific contexts and, for our purposes, continue to exist as completely valid parts of the Star Wars franchise network, emerging out of the the interaction between fan and industry discourses of canon and continuity.

The examples discussed above should not be understood as the powerful entertainment industry making concessions and granting the wishes of lowly fans rather, these are representative of the process of meaning-making taking place constantly within media franchises, as ideas and concepts are discursively defined, legitimized, invalidated and reiterated, contributing to and exponentially expanding the network. Although the industry, fans and other groups of users may consider certain parts to be more "official" or "true" incarnations of a franchise, these discourses do not mask the existence of many other versions that are equally relevant to the discussion of franchises as a concept. What is important about industry and fan discourses for the study of franchises is how, according to underlying assumptions and beliefs about the franchise, and via what processes texts and meanings are positioned as legitimate and canonical. There is no one fixed, "official" canon or continuity of any franchise, and such 
distinctions are only meaningful insofar as they are treated as discursive constructs. In studying the frameworks and hierarchies implicitly and explicitly constructed by industry and fan discourses, we must recognize that they are designed to map coherence and continuity onto fundamentally incoherent systems. These discourses, others like them (popular, journalistic, critical, academic, and so on) and the interactions between them shape and define the meaning of a franchise in different ways - each contributing to the larger complex — and constitute the principal object of study when analyzing franchise texts. However, if to study media franchises is indeed to study discourse, it is necessary to move beyond conventional notions of canon and text, and I will pursue this argument in the following chapters. 


\section{CHAPTER THREE:}

\section{BEYOND CANON - APOCRYPHAL FRANCHISE DISCOURSE}

As I have argued leading up to this chapter, it is imperative when considering media franchises to acknowledge the vast diversity of elements and contexts that define their meaning, structure and function. I have already established in Chapter Two that between the various users of a franchise, many different versions and canons are generated through ongoing discourse. In many cases, this results in the abandonment or disowning of certain texts and aspects of a franchise in favour of others, and thus creates a sort of franchise apocrypha - a body of texts and meanings that are no longer (or were never) considered by different groups of users to be "officially" part of the canonical franchise. As I have already pointed out, fan discourse is often considered to be "unofficial," but is an important and meaningful aspect of any franchise. Similarly, rival competing "official" versions of the same franchise (which exist for reasons of copyright or other legal factors) may be included in this apocrypha, along with tributes, parodies, self-referential works, and other non-canonical texts. Like Biblical apocrypha, these texts may not be granted canonicity by True Believers, but must be recognized by scholars to be an important part of the larger construct. In this chapter, I will examine how such texts, in spite of their "inauthentic" apocryphal status, nevertheless contribute to the meaning of the franchise in specific contexts, and therefore must be seen as a relevant part of franchise studies. What is being suggested or implied about franchises by apocryphal texts and their uses? If we situate them within the larger franchise network, 
how do they change and define the meaning of other franchise elements? To begin, I will examine how fan creations and unlicensed commercial products, commonly considered apocryphal, function as a significant discourse within the Star Wars and Lord of the Rings franchises, both of which are popular fodder for such creations. Then, the infamous "Star Wars Holiday Special" will serve as an example of a formerly "official" but now largely disowned text. The 1967 James Bond spoof Casino Royale represents a well-known example of an ambiguously canonical film produced thanks to a legal loophole. I will briefly examine the notion of "official" apocrypha, and I will discuss texts ostensibly beyond the franchise, with particular reference to Son of Rambow (2007). Finally, I will consider how external parodies and "spiritual successors," and similar concepts can also be seen to contribute meaningfully to franchise discourse.

In this first section, I will discuss how non-commercial fan creations and commercial products that are not officially licensed can be situated within franchise discourse, drawing on research by Jenkins and Thompson on Star Wars and Lord of the Rings, respectively. How does the industry itself account for and deal with potentially problematic discourses? How is the existence of "unofficial" versions rationalized or ignored? How do these non-canonical versions of the franchise position themselves in relation to the canon? In many ways, fan creators use franchises in the same way as the industry - drawing on the network of discourses and positioning their work in relation to other franchise elements - albeit for slightly different purposes. Although fan culture generally is actively encouraged by the industry, the products of fan culture, including fan fiction, fan art, fan films, and so on, present the industry with somewhat of a conundrum. 
How can control (however illusory) be maintained over the meaning and intellectual property rights of a franchise without alienating fans and discouraging the high levels of audience engagement and customer loyalty represented by these creations?

The relationship between the industry and the people and communities who create fan works is characterized by Jenkins as tentatively civil at best and outright antagonistic at worst. ${ }^{87}$ In many cases, fan creations are simply ignored by the industry, due to their non-commercial intent, with fan creator communities content to be ignored and to operate slightly below the radar. The large and diverse fan fiction communities that exist online, for example, tend not to be disturbed by the companies behind the various franchises being referenced. Other forms, however, such as fan films, cause the industry more difficulty, especially given the relatively high production values of some works, now that sophisticated equipment and software is more readily available to consumers. ${ }^{88}$ In $T h e$ Frodo Franchise, Thompson discusses at length the relationship between the industry and fans of the Lord of the Rings franchise, including the salacious world of slash fiction. ${ }^{89}$ Thompson sees the industry's approach to fan culture in this case as a balance between control and promotion. ${ }^{90}$ Fans are permitted and even encouraged to create fan works, but a strict distinction is maintained by both fans and the industry between the "official" canon and the "unofficial" apocrypha. Too often, this distinction exists also in academia, and it is a credit to Thompson's scholarship that she includes fan culture in her overview of the franchise, as it is usually treated as a separate sociological phenomenon rather than

87 Jenkins, 151.

88 For example, see "Star Wars Revelations," http://panicstruckpro.com/revelations, that cost over $\$ 15000$ to produce, in spite of being a completely non-profit fan venture.

89 Homoerotic fan fiction.

90 Thompson, 133. 
as a relevant aspect of industrial and franchise discourse.

In Convergence Culture, Jenkins includes a detailed examination of the relationship between Lucasfilm and the Star Wars fan fiction community. Early on, Jenkins observes, there were strict warnings issued to fanzines publishing fiction set in the Star Wars universe, particularly in relation to erotic stories. ${ }^{91}$ Later, with the advent of the Internet and online fan communities, the company attempted to meet fans halfway by offering support and resources for fansites, but also insisting that the rights to any Star Wars-related material drawing upon those resources would be forfeit. ${ }^{92}$ Later still, "official" venues for Star Wars fan films in the form of online hosting and a Lucasfilmrun Fan Movie Challenge became more prevalent, a strategy which Jenkins describes as "incorporation and containment." ${ }^{.93}$ This allows the industry in this instance to cultivate, benefit from, but also tightly control fan culture. The rules for the Fan Movie Challenge are strict, and initially denied entry to straight fictional works, or any film that attempts to seriously expand upon the Star Wars universe - only parodies and other non-serious fan movies were allowed. ${ }^{94}$ Since the time of Jenkins' writing, the relationship between Lucasfilm and fan communities has changed somewhat, and a fiction category is now included in the Challenge. Even so, this represents an effort on the industry's part to control fan culture. The regulations for the Challenge continue to be strict, and include limitations on runtime ("preferably under 5 minutes"), the amount of "official" Star Wars music can be used (two cues, each less than one minute) and on the use of guild- and

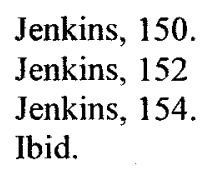


union-affiliated actors and crew (which is prohibited) ${ }^{95}$ Providing an officiallysanctioned but closely monitored venue for fan culture, these regulations effectively allow Lucasfilm to guarantee that Star Wars fan films will be identifiably nonprofessional. Ultimately, the Fan Movie Challenge is a more potent means for Lucasfilm to maintaining control over the franchise, while still appearing to encourage fan culture, than completely disallowing fan films. The distinction between "official" canon and apocrypha is strictly preserved, not only by the industry, but often by the fans themselves.

Like Thompson, throughout Using the Force Will Brooker, argues that fan culture is a meaningful process worthy of analysis. Brooker extensively discusses how Star Wars fan texts (filmic or otherwise) reflect specific conceptions of the franchise and of Star Wars fandom. One particularly interesting pair of examples of fan creation are The Phantom Edit (2001) and Balance of the Force (c2001), both fan cuts of Star Wars Episode I: The Phantom Menace that endeavour to correct the perceived weaknesses of the "official" cut. In these cases, the creators' personal versions of Star Wars are made literal thanks to the accessibility of editing software to consumers. The most commonlycited change in these edits is the reduction and reframing of Jar Jar Binks' role in the film. In The Phantom Edit, his most slapstick scenes and dialogue are removed, and the character (although still very much present) becomes much more secondary to the narrative. ${ }^{96}$ Balance of the Force, by contrast, re-dubs Jar Jar's dialogue to make him a more serious character. Certainly, this indicates the prevalence and intensity of negative fan response to the Binks character that I have already discussed — for many, Jar Jar in

95 "Star Wars Fan Movie Challenge - Guidelines," http://www.atom.com/spotlights/starwars/challenge/infoguide.html.

96 Brooker, 92. (As Brooker notes, yet another fan edit of the film exists that removes Jar Jar Binks entirely.) 
his "official" form simply cannot be reconciled with the franchise. References to midicholrians are also absent from the fan cuts. Other aspects of The Phantom Edit and Balance of the Force are more subtle, but equally interesting and demonstrative of fan visions of the franchise. For example, Mike J. Nichols, who created The Phantom Edit, frames his work thusly:

[ $\mathrm{t}$ ]his project began as a personal endeavor when I watched 'The Phantom Menace' as an audience, analyzed it with the care and attention of a Lucas team member, and carefully re-edited it, concentrating on creating the storytelling style that Lucas originally made famous. ${ }^{97}$

For Nichols, the act of modifying the "official" Episode I text is in fact an appeal to a higher, more pure "official" version, that of the earlier trilogy. Note especially how Nichols aligns himself with the "Lucas team" and suggests that Lucas himself has abandoned the style upon which he built his career. For Nichols, it is perfectly acceptable that the "true" version of The Phantom Menace text (his own edit) might come from outside of Lucasfilm because he as a fan knows better than Lucas himself now does how to handle the franchise. This represents the divorcement of the franchise itself from its creators and from the "official" version, and yet still adheres to a strict alternative canon and vision of Star Wars.

In Balance of the Force, the pod race scene is reworked, which similarly highlights a particular conception of the franchise: while the "official" cut features virtually no music (in homage to the similar race scene in Ben-Hur [1959]), the fan edit adds a persistent John Williams score in attempt to make the film more exciting and more

97 Daniel Kraus, "The Phantom Edit: How one "Star Wars" fan nearly fixed the "Episode 1" disaster, and why George Lucas is indirectly stoking another kind of digital revolution," Salon.com, http://archive.salon.com/ent/movies/feature/2001/11/05/phantom edit/index.html. 
"Star Wars." Rather than suggesting that the cinematic allusion was lost on the creators of the fan edit, I would argue that perhaps for the creators, cinematic allusion (whether recognized or not) is simply not an important aspect of Star Wars. Evidently, intertextual reference and homage is a major aspect of not only Star Wars, but of cinema more generally for George Lucas himself, who is often cited as an exemplar of the "film brat" generation. Film buffs, scholars, and some other users versed in the canon of cinema may also share this perspective. However, for many fans (and certainly for mainstream audiences) these references may not even be apparent, which changes the meaning of Star Wars in significant ways — rather than a post-modern pastiche of high- and low-culture cinematic conventions and mapped onto Joseph Campbell's monomyth structure, Star Wars can easily be seen as a straightforward romantic epic and as a continuous fantasy storyworld. For the anonymous creators of Balance of the Force, the pod race is not an intertextual reference, but is a Star Wars action sequence that, like other sequences in the franchise, cries out for an exciting John Williams score. As Brooker notes, The Phantom Edit and Balance of the Force may also be an example of amateur film-makers using fan creations as calling cards in a bid for industry success, working within the familiar franchise as a way of drawing attention to new talent..$^{98}$ In this context, fan culture and creation is seen as a gateway to a future career and to opportunities working on original properties. In any case, The Phantom Edit and Balance of the Force are a interesting examples of how fan creations of all stripes can offer unique insights into the nuances of franchise discourse.

The above examples are all non-profit fan ventures. Unlicensed commercial uses

\footnotetext{
98 Brooker, 175.
} 
of franchises, on the other hand, are usually served quickly with cease and desist notices, although the boundaries of fair use and parody are often hotly debated in these situations. ${ }^{99}$ In other cases, however, parody is actively encouraged, such as the fullepisode Star Wars spoofs on the popular television series That '70s Show, Robot Chicken and Family Guy — the latter two of which were apparently directly approved by George Lucas — not to mention Lucasfilm-sanctioned feature film spoofs like Spaceballs (1987). ${ }^{100}$ Although these parodies are evidently considered non-canonical, an unfortunate double standard is created by this approach, as no fan film would ever be allowed to air on commercial television for profit. In any case, there are inevitably loopholes that allow for third-party creators to contribute to the franchise network, whether as fans or for commercial purposes, and these apocryphal elements (not to mention the industrial and critical reactions to these elements) contribute no less to the overall discourse. The meaning of a franchise extends far beyond the "official" canon, and the kind of unlicensed apocrypha I have discussed here constitutes a valuable object of study.

"The Star Wars Holiday Special" is in many ways the definitive apocryphal franchise text, and certainly the most notorious in the Star Wars franchise. Fully licensed but produced by $20^{\text {th }}$ Century Fox Television for CBS without the involvement of George Lucas or Lucasfilm, the special was a two-hour variety show with decidedly low production values featuring live action and animated segments, along with musical

99 For example: "Cease and Desist," http://slashboing.blogspot.com/2006/11/cease-and-desist.html.

${ }^{100}$ Mike Snider, "'Robot Chicken' digs its satirical talons into 'Star Wars'," http://www.usatoday.com/life/television/news/2007-06-12-robot-chicken N.htm, Bonnie Burton, "Family Guy' Creator Reveals Star Wars Cred," http://www.starwars.com/community/news/rocks/f20070921/index.html. 
numbers and other attractions. The show featured most of the principal cast of Star Wars (1977) along with special guests including Bea Arthur, Art Carney and then-popular band The Jefferson Starship, and is vaguely centred on Han Solo and Chewbacca voyaging to the home planet of the wookiees, Kashyyyk, to celebrate "Life Day." The special was met with poor reviews, and although it has never been officially released on home video, has widely circulated, first on VHS taped from television and later on the Internet. Since 1978 , it has become both an object of derision and of ironic enjoyment for Star Wars fans, and is not generally considered to be an "official" part of the Star Wars franchise. Why, then, is the apocryphal "Star Wars Holiday Special" relevant? Firstly and perhaps most importantly, in its original 1978 context, the special represents an early and since abandoned notion of what the Star Wars franchise was and could have been. Even with two years to go before The Empire Strikes Back (1980), the nascent franchise existed in many fundamentally different versions, and the "Holiday Special" reflects a vision of Star Wars that certainly did not last. Consider the following excerpt from the official production notes:

The two-hour visual and audio delight stars the cast from the hit motion picture, "Star Wars," along with special guest stars in a live-animated-musical-pot pourri of pure entertainment complete with astonishing electronic special effects.

Guest stars from the original motion picture include Mark Hamill (Luke Skywalker); Harrison Ford (Han Solo); Carrie Fisher (Princess Leia); Anthony Daniels (C3PO); Peter Mayhew (Chewbacca); R2D2 (played by R2D2); and the voice of James Earl Jones as Darth Vader.

Interplanetary guests are Beatrice Arthur as the proprietor of the wackiest bar out-of-this-world; Art Carney, as an 
other-worldly door-to-door salesman; The Jefferson

Starship; Harvey Korman in variety of weird personalities, including Chef Gormaanda, "The Julia Child of the Milky

Way," and Diahann Carroll singing an original

composition. ${ }^{101}$

Evidently, the promo reflects a different understanding of Star Wars: less sci-fi/fantasy epic, and more family-friendly adventure — not a wrong understanding, but a different one. At this time the family-friendly approach to Star Wars is understandable, given the success of the first film and the heavy youth-oriented merchandising the franchise was receiving. In fact, the notion that guest stars, musical numbers and so on are incompatible with the Star Wars mythology did not disappear with the special, and throughout the 1980s media, merchandise and marketing related to the franchise adopted this sort of approach — including a 1980 album of holiday-themed music, "Christmas in the Stars: Star Wars Christmas Album.."102 I would argue that in spite of its omission from most versions of the franchise canon (whether due to obscurity or derision), "The Star Wars Holiday Special" can tell us much about how Star Wars was understood by the industry and by consumers in the specific context of the late 1970 s and early 1980 s.

The "official" positioning of the special has evidently changed significantly, in the wake of five additional Star Wars films, countless new narrative and non-narrative extensions and a vastly expanded fan culture. "The Star Wars Holiday Special," in spite of this constant expansion, has never been completely abandoned by Lucasfilm, and like many apocryphal texts exists in limbo between "official" and "unofficial" status. There is a persistent rumour suggesting that George Lucas himself despises the special and once

101 The Star Wars Holiday Special, "Official Production Notes," http://www.starwarsholidayspecial.com/text/production notes.htm.

102 Which incidentally features Jon Bon Jovi's professional recording debut on "R2-D2 We Wish You a Merry Christmas," in an interesting example of overlapping networks of meaning. 
claimed that if he had the time and a hammer, he would destroy every copy. The veracity of this story is questionable, and many variations exist, but needless to say it reflects the lack of clarity and certainty with regards to how the Lucasfilm company handles the existence of the special and of where it fits into their "official" version. However, in spite of its omission from most accounts of the franchise, many aspects of the special are in fact considered canon, according to Lucasfilm's internal continuity database, The Holocron. Rather than removing the special from continuity (and thus "existence") as I have described in other cases, it is considered to be "S-canon," indicating that although the events portrayed are non-canonical, certain elements that are not inconsistent with the larger continuity "count" as canon. ${ }^{103}$ The wookiee's home planet of Kashyyyk, for example, Chewbacca's family and other information that has been ratified by more "official" texts are considered valid. Because the special is considered at least partially canonical, it has not been completely disowned - but at the same time, it is never fully embraced, and occupies a tentative place in the "official" Star Wars discourse. This hesitance to completely abandon apocryphal texts reflects the more general tendency in the Star Wars franchise towards maintaining (or attempting to maintain) one single continuous timeline within which all Star Wars media can be incorporated. Ironically, Lucasfilm's apparent hesitance to disown or make redundant any instance of Star Wars completely has caused the franchise to be fraught with ambiguously canonical texts such as "The Star Wars Holiday Special" and other similar examples. ${ }^{104}$

${ }^{103}$ Chris Baker, Wired, "Meet Leland Chee, the Star Wars Franchise Continuity Cop," http://www.wired.com/entertainment/hollywood/magazine/16-09/ff starwarscanon?currentPage=all.

104 The early Star Wars novel Splinter of the Mind's Eye (1978), for example, includes references to a physical relationship between Luke Skywalker and Princess Leia, who had not yet been established to be siblings. This apocryphal incident of incest, like the "Holiday Special" has never been completely removed from the canon. 
The relevance of "The Star Wars Holiday Special" to the larger franchise extends beyond this specific context, however, because as the franchise changes and expands, it continues to exist not only in the memories of those who had seen it in 1978, but in circulation among Star Wars fans and other film buffs. As such, the meaning of the special is not fixed, but like the franchise itself varies over time depending on context. As noted above, contemporary fan discourse tends to treat the special ironically, as an unintentional, so-bad-it's-good bastardization of Star Wars. Not unlike other maligned aspects of the franchise discussed in Chapter Two (such as Jar Jar Binks and midichlorians), the Special is seen as an abortion of the "true" Star Wars, but simultaneously is a source of amusement and even pride. Ottawa film-maker Lee DeMarbre recalls screening the special at a local nightclub to sold-out crowds as an annual event for several years:

[p]eople loved to hate the show. I would fast forward certain segments if people booed loud enough [...] I'd say to the audience that as Star Wars fans we have to learn to suffer ... we suffered threw [sic] the Ewokes [sic], Jar Jar Binks, and Hayden Christensen [sic] ... now suffer threw [sic] the Holiday Special. ${ }^{105}$

DeMarbre, like many Star Wars fans, treats the special with an ironic affection, and his rowdy screenings are emblematic of an approach to Star Wars — or aspects of it - as nostalgic kitsch rather than as sincere, sacrosanct mythology. Similarly, numerous websites specializing in fan-oriented humour feature satirical critiques and spoofs of the special. The "love-to-hate" approach described by DeMarbre is very much present in these articles: I-Mockery.com begins its review by asking, "Are there words that exist

${ }^{105}$ Lee DeMarbre, "Re: Star Wars Holiday Special," e-mail to author, January 15, 2009. 
which [sic] can accurately describe the pain I associate with viewing this so-called special? Probably not."106 "The Nitpicker's Guide to The Star Wars Holiday Special" at Chefelf.com likewise suggests that "[u]pon actually seeing it, your faith in God (if it existed) is shattered. If you had no faith in God you may begin to search for it." ${ }^{" 107}$ Both sites use the special as fodder for a wide variety of hyperbolic critiques and off-colour jokes, and feature unflattering stills with funny captions, jabs at Lucas and the prequel trilogy, and comic quips about the travails of long-suffering Star Wars fans. Although Lucas' company apparently had next to no involvement with the production, he still receives much of the blame for it, much as he is personally vilified in relation to the prequel trilogy. In other media, the special is referenced comically in a variety of pop culture- and fandom-savvy TV shows and parodies such as the Robot Chicken Star Wars episode. By examining the Holiday Special through these contemporary fan discourses, we can see how the mode and tone of engaging with the Star Wars franchise shifts fluidly depending on context, even for individual fans - an understanding of fandom that is somewhat different from the stereotypical, self-serious and rabid dedicate.

Another form of franchise apocrypha is caused when competing versions of a franchise exist or are created by copyright issues, rather than being disowned. The James Bond franchise is a useful example in this case, due to the historically murky legal status of certain aspects of the franchise. In particular, the rights to film the first 007 novel, Ian Fleming's 1953 Casino Royale have changed hands so many times that several

\footnotetext{
${ }^{106}$ I-Mockery, "The Star Wars Holiday Special," http://www.i-mockery.com/minimocks/starwars-holidayl.

${ }^{107}$ Chef Elf, "The Nitpicker's Guide to The Star Wars Holiday Special," http://chefelf.com/starwars/holiday intro.php.
} 
adaptations exist. As I have argued, each of these distinct versions in turn exists in many different discursive versions, the meaning of which can change radically over time and depending on context and use. The earliest version of James Bond to be filmed was a 1954 television adaptation of Casino Royale as part of the series Climax! The one-hour long episode, like "The Star Wars Holiday Special" represents an alternative vision of the Bond franchise - most noticeably, 007 is an American secret agent nicknamed "Card Sense" Jimmy Bond. The Climax! episode is now usually seen as a non-canonical oddity of interest only to the most dedicated of Bond fans, but in its 1954 context was in every sense a "legitimate" and "official" new Bond text — indeed, the only "official" filmed version of James Bond. Eventually, after failed attempts to produce a screen version of Casino Royale, the rights came to lie with producer Charles K. Feldman. By this point, the "official" EON/MGM Bond franchise was successfully underway, and when the producers declined Feldman's offer to produce Casino Royale as part of that version of the franchise, Feldman decided to produce the film as a spoof under Columbia, rather than enter into direct competition with other Bond films. ${ }^{108}$ The 1967 version of Casino Royale, therefore, is legally an "official" Bond film but simultaneously considered noncanonical because it is distinct from the EON/MGM films.

Casino Royale (1967) is an interesting example of franchise apocrypha that raises a variety of different questions about franchise discourse. Like other parodies, its selfreferential lampooning of the "official" Bond movies reflects the culture and discourses surrounding James Bond in the 1960s, as the franchise reached new heights in popularity

${ }_{108}$ Robert Dassanowsky, "Casino Royale," Film Reference, http://www.filmreference.com/Films-CaChr/Casino-Royale.html. 
and box office success. Although the spoof itself did well at the box office, for many years, the film was positioned by the industry and by fans as "unofficial", along with the Climax! episode, as a dalliance and a novelty that did not constitute an authentic James Bond experience. Now, however, with EON/MGM finally having produced an "official" version of Casino Royale in 2006, the discursive positioning and meaning of the 1967 film has changed in several key ways. Perhaps most importantly, in 1999 MGM sued Sony Pictures (which now owns Columbia) for the rights to the 1967 version of Casino Royale and to future filmed versions of the novel. ${ }^{109}$ Sony Pictures had teamed with Kevin McClory with the intention of producing a new, alternative James Bond franchise to compete directly with MGM. McClory, who had jointly produced Thunderball (1965) with MGM/EON and Never Say Never Again (1983, another legally "official" but noncanonical Bond film which is now owned by MGM) separately with Warners, claimed to have the rights to the Bond character. ${ }^{110}$ The two studios eventually settled out of court, with MGM relinquishing its partial rights to the Spider-Man franchise, and receiving full rights to not only Casino Royale (1967) but also to the Climax! Episode. A statement by MGM's chairman made clear the studio's approach to franchise apocrypha: "[t]he end of this case reaffirms that James Bond resides at one address - that of MGM and Danjaq [the company that owns EON], his constant home for the last 37 years."111 In a discursive move reminiscent of a comic book retcon, this statement indicates that the newly ratified distinction between "official" and "unofficial" Bond texts was a foregone conclusion for the studio (and indeed, for many fans).

\footnotetext{
109 James Sterngold, "Sony Pictures, in an accord with MGM, drops its plan to produce new James Bond movies," New York Times, March 30, 1999.

110 Ibid. (His claim was eventually refuted.)

111 Sterngold.
} 
However, as discussed in Chapter Two, the drive to impose order on the fundamental incoherence of franchise discourse is abundantly clear in the above quote. In reality James Bond has not resided at one address, and the "official" apocryphal versions of Casino Royale had only retroactively been incorporated into the EON/MGM version of the franchise - and even then, they occupy a space separate from that of the canonical Bond films. This ambiguous positioning is made only more confounding by the new "official" version of Casino Royale produced by EON/MGM in 2006. This newer film evidently cannot be accorded the discursive status of "remake" (for to do so would be to indirectly validate the previous non-canonical versions), and so the 1967 and Climax! versions of Casino Royale, now owned by MGM, are positioned as alternative but not "unofficial" instances of the franchise. To whit: the Climax! episode is included on an MGM-distributed $40^{\text {th }}$ anniversary special edition DVD of Casino Royale (1967), and has even been acknowledged in "official" MGM histories of the Bond franchise in the form of DVD and Blu-Ray special features for Casino Royale (2006). This complicates the conventional notion that the legal copyright holders of a franchise or intellectual property determine the "official" version, for not only have multiple copyright holders existed and produced James Bond media simultaneously, formerly competing texts that were not considered to be part of the same canon have been united as part of an almost-singular version of the franchise. Additionally, the meaning of Casino Royale (2006) is inexorably linked to those previous versions, if only through its reaction against them, and is made more complicated by its positioning as a pseudo-prequel to and pseudo-reboot of the existing EON/MGM films and the re-publishing of the original novel in a new edition to 
coincide with the film's release. ${ }^{112} \mathrm{~A}$ similar, and perhaps even more daunting, complexity can be found in franchises centred on public domain characters and stories, such as Sherlock Holmes, Tarzan and Robin Hood, that allow numerous equally legal and "official" versions of the franchise to compete and exist simultaneously. Within each individual version, all other versions are deemed to be apocryphal or "unofficial," discursively creating an increasingly dense network of radically different meanings. Like the abandoned texts discussed in the previous section, the apocrypha created by competing versions of the same franchise can help us to contextualize and highlight the many and varied aspects of that network.

Some franchises include "official" apocrypha — sub-series or otherwise demarcated texts and products that are "official" in the sense of being authorized by the principal copyright holders but are not considered canon. Indeed, these brands are marketed explicitly based on their non-canonicity, as fanciful alternatives to familiar instances of the franchise. Marvel Comics, for example, publishes a line of comics under the heading "What If...," the first issue of which featured the question, "What If SpiderMan Joined the Fantastic Four?" Marvel's Distinguished Competitor publishes a similar line known as "Elseworlds" that specializes in alternate-universe takes on popular DC heroes. The Elseworlds story Superman: Red Son retells Superman's origins, the baby Kal-El having landed in Soviet Russia instead of Smallville, USA, and posits a very different version of Superman's world. Both Marvel and DC have incorporated similar

112 The direct narrative continuity between Casino Royale (2006) and Quantum of Solace (2008), uncommon previously in the EON/MGM Bond franchise, could be seen as an attempt to further establish Casino Royale (2006) as the "official" film version of that novel. 
alternate-universe stories into "official" canon and continuity — Marvel's 1602, which resituates familiar heroes in the Elizabethan period, is considered canonical and is rationalized into the main Marvel Universe continuity — but What If... and Elseworlds are uniquely positioned as deliberately apocryphal. The Star Wars franchise has also produced an "official" apocrypha, known as "Infinities," that includes comics in which key moments of the Star Wars films are changed - the Death Star is not destroyed in $A$ New Hope; Luke dies in the frozen wastelands of Hoth in The Empire Strikes Back; in Return of the Jedi Darth Vader is redeemed and appears in a white costume. Like the other franchise apocrypha discussed in this chapter, "official" apocrypha can speak volumes about a franchise in certain contexts. The discursive positioning of noncanonical stories within a franchise illuminates clearly how continuity is constructed and maintained, while also demonstrating the interaction between fan and industrial discourses (as indicated by the first issue of Marvel's What If..., which describes the comics as "the most offbeat series of all times [sic]... featuring the stories your letters have demanded!!" The emphasis on fan service here is very much in keeping with the spirit of other "official" franchise apocrypha, and suggests discursive collaboration while still attempting to maintain strict control over canon and continuity. More generally, these texts actively and often self-reflexively play with the mythology and conventions of specific franchises, and the discourses circulating through and around "official" apocrypha actively create and expand the meaning of a franchise.

The examples discussed thus far in this chapter are not difficult to link to their 
respective franchises - few would argue that there is no connection, however apocryphal, between Casino Royale (1967) and the "official" EON/MGM films, or between the "official" Superman and Superman: Red Sun. But how far can we extend our analysis of media franchises? Are texts and discourses that ostensibly lie outside a franchise relevant or meaningful in this context? In this section, I will attempt to push the boundaries of our understanding even further beyond the neatly encapsulated distinctions of canon and continuity. For example, I would argue that a film such as Son of Rambow (2007) is potentially no less important to the Rambo franchise as the "official" Rambo films themselves. Son of Rambow tells the story of an imaginative but sheltered young boy in 1980s England who accidentally sees First Blood (1982), the first Rambo film. Never having seen a movie before, the boy's young mind is ignited and he becomes obsessed with the violent, exciting world of Rambo. With the help of an enterprising but delinquent new friend, who sees potential of this creative energy, the boy sets out to create his own Rambo movie with a VHS camcorder. The fan film-within-a-film, featuring the son of Rambow (the spelling error is deliberate on the part of the filmmakers) and the Colonel attempting to rescue a captured and elderly Rambow, grows out of control as more and more people become involved, which exacerbates the relationship between the two boys.

Son of Rambow is not only a film about imagination, inspiration, friendship and growing up - it is also a film about fandom and franchises. Like real-world fan films, texts like Son of Rambow represent specific visions of the franchise and its appeal, contextualized by both its fictional setting and its real-world occasionality. I would argue 
that such texts also play into the franchise network, creating and defining it in much the same way as "official" discourses. The version of Rambo presented in Son of Rambow is a very particular one - the film is set in the early $1980 \mathrm{~s}$, before the release of Rambo:

First Blood Part II (1985) and thus before the stereotypical version of Rambo - machine gun in hand, muscles bulging, mowing down hordes enemy soldiers — is fully established. Additionally, due to the sheltered perspective of the main character, his version of Rambo is not contextualized within American culture and history, within film genre, or most importantly within the basic conventions of fandom. For the young protagonist, First Blood is cinema in its entirety, and the Rambo franchise is a boundless imaginary playground that is fully integrated not only with his own ideas but with his own life - in this apocryphal context, a deadly flying dog and the quest for a lost father figure are absolutely valid and essential aspects of the nascent franchise. This shift in context is shared partially with the audience, as the events are shown from the young boy's peculiar perspective, but not entirely, for we, like the film-makers, are aware of the subsequent development of the franchise in novels, films and other media, and of the cultural tropes that have come to be associated with Rambo and other hard-body action heroes of the 1980s. Indeed, for some audiences, Son of Rambow could not but foreshadow the "official" franchise's return to screens after a lengthy absence in Rambo (2008) a year later.

While on a textual level the film presents a fictionalized apocryphal version of Rambo(w) in the minds of its characters, it also implies a particular approach to the franchise that can be seen to contribute to the meanings circulating in the larger franchise 
network. Perhaps most importantly, the film positions the Rambo franchise as an object of fun - silly, over-the-top, anarchic and explosive fun. Although this understanding is quite separate from the "official" franchise discourse, which is largely self-serious and concerned with the manly and morally ambiguous business of war and post-traumatic stress disorder, I would argue that Son of Rambow quite accurately reflects a mode of reception that many viewers share. For many of us, the Rambo films are absurd but enjoyable exercises in visceral action, bad acting and pyrotechnics, and indeed the cultural stereotype of the muscle-bound, machine gun-toting behemoth is often invoked in these self-reflexively positive terms by fans. Son of Rambow invites the audience to embrace the imaginative excitement of Rambo instead of its serious intention, and in doing so re-creates the franchise in a certain image. Similarly, films like Trekkies (1997), a documentary about Star Trek fans and Fanboys (2009), a comedy about Star Wars fans, define and elaborate those franchises respectively. By the same token, films and texts that include homages to specific franchises whether directly or through narrative or stylistic reference, such as the invocation of The Empire Strikes Back in The Lord of the Rings: The Return of the King (2003), that has Legolas dispatching oliphants in a similar manner to Luke Skywalker destroying Imperial AT-AT walkers on Hoth, expands both franchise discourses in interesting and meaningful ways. Textual tributes to (and meditations on) franchises and fan culture, therefore, can easily be seen as a relevant part of the franchise network, rather than as external commentary.

Another similar form of apocrypha that often plays directly into franchise 
discourse is the spiritual successor - texts that are tangentially related to a franchise through means other than direct narrative connection. In the broadest terms, texts that are connected to a franchise according to parameters inconsistent with the dominant discourse of canon and fictional continuity are kept separate but granted special status as spiritual successors. Extratextual factors such as authorship, or textual factors such as style and tone are seen to have crossed outside of the franchise and into the new text, whether deliberately or simply by grace of common features. One example of the former is the Nintendo 64 video game Perfect Dark (2000), which was widely considered to be the spiritual successor to the James Bond video game Goldeneye 007 (1997), itself a version of the eponymous 1995 film. Both games were developed by Rare, a thensuccessful company, and Goldeneye had been a hugely popular release. Rather than further pursuing the Bond franchise, Rare instead moved on to an original, futuristic action/sci-fi franchise with Perfect Dark. The new game used the same engine as Goldeneye (the same basic coded framework), and faithfully recast many aspects of the earlier game's gameplay in a new fictional setting with enhanced audiovisuals and programming. In particular, the wildly popular multiplayer component of Goldeneye is recreated and expanded upon in Perfect Dark, and features numerous references to its predecessor, including several familiar levels, characters and weapons (explicit references to James Bond are, of course, masked). Like Goldeneye 007, Perfect Dark was wellreceived by gamers and in many cases was seen as a logical replacement for the earlier game. The lack of narrative connection notwithstanding, the games are often positioned as intrinsically connected. ${ }^{113}$ The Goldeneye video game cannot be separated from the ${ }^{113}$ IGN, "Perfect Dark," http://uk.ign64.ign.com/articles/153/153906pl html. 
James Bond franchise, and therefore by extension we must acknowledge the discursive link between the Bond franchise and the Perfect Dark franchise. A later Rare video game series, TimeSplitters, bears a similar discursive relationship to Goldeneye and Perfect Dark and thus to the Bond franchise. As I have already argued, the lines that define the boundaries of a franchise are far from precise, and apocryphal discourses can extend far beyond the commonly accepted canon while still meaningfully and actively defining the franchise.

Another text that has a "spiritual" relationship to the Bond franchise is the 2001 film The Tailor of Panama, a spy thriller that stars Pierce Brosnan (who at the time was still EON/MGM's James Bond), as an MI-6 agent. Already, the link to the Bond franchise is established by coyly casting a Bond actor as a British spy. More interesting, however, is the tone and presentation of the Brosnan character, who is a crass, unkind, untrustworthy and womanizing brute exiled to Panama for having an affair with a diplomat's mistress. The character can easily be seen as the anti-Bond, stripping away the excitement, charm and glamour of the franchise and presenting a version of the fantasy much more grounded in the real. This self-consciousness not only plays with Brosnan's star persona, but also engages with the Bond franchise itself by presenting an image of the famous 007 in negative. The Tailor of Panama positions itself against a particular "official" version of Bond, and in doing so situates itself, however apocryphally, within the franchise discourse. Like Son of Rambow, the film expands and refines the network by presenting an alternative vision of the franchise inexorably linked to the "official" version. Similarly, the 2006 remake of The Pink Panther featured actor Clive Owen as 
Agent 006 in an overt parody of James Bond - a parody made more significant by the real-world attention Owen received when Daniel Craig was cast as Bond, in spite of Owen's status as the widely-accepted popular choice. In both these cases, references to extratextual information create a discursive link to the Bond franchise.

I would extend this understanding to other parodies as well, both authorized and unauthorized, which engage with franchise discourse in analogous ways. As has already been noted, both the stop-motion animated comedy program Robot Chicken and Family Guy (among many other television shows) have featured many Star Wars parodies in various episodes, and even have gone so far as to produce entire episodes dedicated to affectionately lampooning the franchise. One scene in the Robot Chicken episode includes a long-suffering Emperor Palpatine mockingly rolling his eyes while Darth Vader whines about his problems over the telephone in reference to the perceived "wimpiness" of Anakin Skywalker in the prequel films. In much the same way as ironic screenings of "The Star Wars Holiday Special" and some fan-films, this kind of parody reflects a self-conscious fandom that "loves-to-hate" as many aspects of the franchise as it loves. Family Guy has incorporated well-known scenes and dialogue from Star Wars (as well as other franchises, such as Indiana Jones), into the narrative of several episodes. For example, one episode ends with Peter Griffin receiving a medal for heroics, and the sequence plays out as a virtually shot-for-short recreation of the well-known ending of $A$ New Hope, with various Family Guy characters substituted. As the sequence progresses, actual Star Wars characters also appear, and the end credits for the episode are presented in the same manner as the Star Wars films. Less overt parody than ironic homage, scenes 
like this one rely almost entirely on the cultural familiarity of the franchise, and indicate the extent to which a franchise can become ingrained in the cultural consciousness. More importantly for our purposes, such ironic and parodic references reflect popular conceptions of well-known franchises. As noted above, the comic stereotype of Rambo, as presented in countless parodies, is an eminently relevant part of that franchise, just as Arnold Schwarzenegger's famous and much-lampooned "Ah'll be bah-ck" line from the Terminator franchise defines the entire franchise for many people — parodies in films such as UHF (1989) and Hot Shots Part Deux (1993), pornographic knock-offs of popular franchise films, and countless television and Internet spoofs, as well as selfparodies like The Last Action Hero (1993) and True Lies (1994) are all vital to the discursive construction of these franchises in certain contexts. Such familiar Star Wars tropes as "use the Force, Luke" or "No, Luke, I am your Father" are therefore as much a meaningful part of the franchise as the narrative contexts in which they were introduced.

Throughout this chapter, I have argued for a questioning of the distinction between canon and apocrypha in media franchises, as well as the radical expansion of what constitutes a franchise. Those texts that are not considered canonical (and the reasons for their exclusion) represent discourses that are very much a part of the overall franchise. Indeed, in some cases the apocrypha of a franchise can yield insights into the meaning of a franchise in particular contexts that might not otherwise be apparent within the canon. In addition to fan fiction and other fan-produced texts, disowned texts such as "The Star Wars Holiday Special," competing versions such as Casino Royale (1967) and Never Say Never Again, tribute texts and homages (affectionate or otherwise) such as Son 
of Rambow, spiritual successors such as Perfect Dark and franchise parodies, I would extend this argument to a wide variety of other apocryphal texts. Works within a filmmaker or actor's oeuvre but outside the franchise (George Lucas' and Harrison Ford's work on both the Star Wars and Indiana Jones franchises, for example), franchise texts retconned out of continuity (such as earlier Star Wars books that gave accounts of Boba Fett's background since rendered non-canonical), the many different possible endings and meanings generated through video game play (consider the divergent Dark Side and Light Side endings that exist in many Star Wars games), and texts that are seen to be influential on a franchise (Kurosawa's The Hidden Fortress (1958) is often cited as a prime influence on $A$ New Hope), are all apocryphal or otherwise non-canonical texts generally kept separate from the franchise canon, which might upon examination prove to be valuable to the study of a franchise. Such apocryphal texts cannot be divorced from the franchise - simply put, in order to fully understand the Star Wars franchise, it is necessary to understand how Spaceballs is a part of it. 


\section{CHAPTER FOUR:}

\section{BEYOND TEXT — EPHEMERAL FRANCHISE DISCOURSE}

In late 2007, John McClane's run for president of the United States was announced. The seasoned New York cop, protagonist of the Die Hard franchise, was immediately positioned as a no-nonsense everyman perfectly suited to the problems of the nation. In fact, the idea of John McClane running for president is an Internet meme that emerged during the 2007-2008 presidential campaign, partially in relation to the promotion of Live Free or Die Hard (2007), the most recent film in the franchise, on DVD and Blu-Ray. According to the Wikipedia, "[t]he term Internet meme is a neologism used to describe a catchphrase or concept that spreads quickly from person to person via the Internet." ${ }^{114}$ Internet memes are by nature ephemeral, transient and fleeting, associated with a particular time and context and not intended to last. Following the discussion of apocryphal franchise discourses in the previous chapter, in this chapter I will extend our understanding of media franchises even further, not only beyond the discourse of canon, but also beyond the limitations of the text itself. As Miller, Bennett and Woolacott each argue, extra- and non-textual factors are vitally important to the production of meaning in discursive networks. I have already argued in Chapter Two that marketing and promotional materials are a key aspect of industrial discourse in relation to franchises, and I have alluded to the importance of ephemeral discourses such as the Han Shot First movement, but the notion of franchise ephemera includes all that is non-narrative and non-textual and is seen as separate from or peripheral to the "official" franchise,

114 Wikipedia, "Internet meme," http://en.wikipedia.org/wiki/Internet_meme. 
including fan and mainstream popular discourse, DVD extras, newspaper articles, television tributes and retrospectives, merchandise and branded products of all kinds, and so on. In spite of their marginal positioning in relation to the franchise canon, these ephemeral discourses are ripe for study and like apocryphal discourses can yield valuable insights into the contextual meaning of a franchise.

In this chapter, I will analyze the McClane for president meme in its numerous iterations and contexts, in relation to the larger media franchise constituted by the Die Hard films, video games, merchandise and so on. By bringing this ephemeral aspect of the Die Hard franchise to the fore, I will demonstrate how in order to fully understand media franchises, we must not limit ourselves to traditional notions of text. Additionally, I will demonstrate how, as I have noted throughout this thesis, the meaning and function of different parts of a franchise is highly contingent on context and use - occasionality, according to Miller. Although linked by their association of John McClane with the US presidential race, the various iterations of the meme, both "official" and "unofficial," represent notably different versions and understandings of the franchise and what it means. How and for what purpose - political, satirical, commercial and otherwise - is the meme used on websites and by Internet users? The $20^{\text {th }}$ Century Fox-sanctioned, "official" presentation of the meme is different in key ways from some of the unlicensed third-party versions, using both the meme and the franchise for decidedly different purposes. To begin, I will examine Fox's "official" version, and will subsequently address an assortment of "unofficial" iterations, comparing and contrasting each. In this final extended case study I will bring together the key points of my thesis: the inclusion of 
non-canonical and non-textual elements in the understanding of franchises, the acknowledgement of many different, often incoherent contextual versions and meanings within franchises, and of course the underlying concept of franchises as discursive networks.

The "official" iteration of the McClane for president meme (and apparently the earliest), is a website called "A Nation For Change," "115 that went live in November 2007, shortly after the DVD and Blu-Ray release of Live Free or Die Hard. ${ }^{116}$ The only direct connection between Fox and the website is a link on Fox's Live Free or Die Hard DVD website featuring an image of McClane and the text, "McClane For President: A True American Hero." ${ }^{117}$ Beyond this link, the campaign is not referenced on the DVD website, and on A Nation For Change, there is no obvious reference to the official marketing of the film. This positions the site as a basic example of the ambiguous, arm'slength "viral" marketing style that has become increasingly prevalent in recent years. ${ }^{118}$ In fact, the only indication for the average viewer that the site is officially licensed (other than the high level of polish and production value) is that visitors can sign up for news about Fox products. The site was designed and built by at least two outsourced companies, Neoganda and Silent7, commissioned by the Fox Intellectual Property Department, and features a variety of information and activities for visitors. ${ }^{119}$ The

115 "Yippie Kay Yay, America!," http:/www.anationforchange.com/. See also the campaign's MySpace page, that reproduces much of the same information at http:/www.myspace.com/johnmcclane4president.

116 Domain Tools, "Whois Record for Anationforchange.com," http:/whois.domaintools.com/anationforchange.com.

117 "Live Free or Die Hard," http://www.livefreeordieharddvd.com/.

118 Other examples of viral marketing include the online marketing for The Blair Witch Project (1999), and the spray-painting of biohazard symbols on city streets to promote 28 Weeks Later (2007).

119 Silent7, "Die Hard DVD: Elect John McClane," http://www.silent7.com/index.php?/interactive/diehard-dvd-elect-john-mcclanel. 
strategy of reintroduction mounted by Live Free or Die Hard is very much present here, as the franchise is positioned both as a nostalgic classic and as cool and contemporary.

Across the top of the homepage of A Nation For Change, naturally done up in red, white and blue, is a large banner proclaiming "YIPPIE KAY YAY, AMERICA!" The less profane take on McClane's famous catch phrase ${ }^{120}$ is followed by the more modest statement, "Elect John McClane for President '08." The page is a superficial mock-up of a real politician's website — pull quotes and bold statements abound, with large, colourful images taken from Live Free or Die Hard and stock photos. Other slogans on the site include "McClane: The Right Man for the Wrong Time," in reference to dialogue and taglines from the Die Hard films, and "John McClane is a True American Hero." A "Did You Know?" panel displays a rotation of "facts" about McClane, summing up the plots of the first three Die Hard films and adding that he "has defeated terrorists in elevator shafts on numerous occasions." Visitors are offered two pages of "campaign" information and several activities (for lack of a better word) with which to prolong their time on the site.

The first subsection of the site is titled "The Man," and is intended to be a biographical overview of McClane's career. Below a quote from Live Free or Die Hard in which McClane bitterly laments that being a hero isn't all its cracked up to be is the contrasting statement, "McClane is a True American Hero." The text on this page describes McClane's distinguished service with the NYPD, comments on his troubled personal life ("But what true-blooded American doesn't battle demons like these?"), and asserts that he never lets his problems get in the way of defending America. A summary of McClane's "record" follows, which traces the four Die Hard films and highlights

120 "Yippie kay yay, motherfucker!" 
certain memorable moments from each:

1988 - McClane saved hundreds of people and millions of dollars when he defused a hostage crisis at Los Angeles' Nakatomi Towers. YOU WANT COURAGE? McClane escaped a rooftop explosion by jumping off the side with a fire hose tied around his waist. [Die Hard]

1990 - McClane prevented dozens of airplane crashes including his wife's flight - by foiling a terrorist plot at Dulles International Airport in Washington D.C. YOU WANT JUSTICE? McClane went head-to-head with a terrorist on the wing of a taxiing plane, and he didn't let up until the bad guy got sucked into one of its engines. [Die Hard 2]

1995 - McClane and New York Taxi Driver Zeus Carver thwarted a complicated plot to heist hundreds of millions in gold bullion from the Federal Reserve. YOU WANT RESOURCEFULNESS? McClane survived a helicopter attack by shooting out surrounding power lines to fry the offending aircraft. [Die Hard With a Vengeance]

2007 - McClane teamed up with computer hacker Matt Farrell to stop the greatest cyberterrorism conspiracy in history, saving both his daughter and our nation's infrastructure. YOU WANT RESOLVE? McClane drove an SUV through a building just so he could ram a terrorist down an elevator shaft. [Live Free or Die Hard]

This resume of McClane's history of violence and heroism serves several functions for Fox on the site. First and foremost, the list firmly aligns Live Free or Die Hard with the previous Die Hard movies, positioning it within the canon as a full and worthy successor. Additionally, however, the list serves to validate the franchise canon itself by creating a continuous, unproblematic version of McClane's exploits across four films (but not video games, novels, etc). In citing specific "classic" scenes from each film, this section also attempts to create nostalgia for the franchise as a whole, aligning iconic sequences from 
the earlier films with sequences from the newer films. By the same token, including somewhat less popular characters such as Zeus Carver and Matt Farrell in the chronicle positions them as essential components of McClane's adventures and the internal continuity of the franchise. Around this time a boxed set of the first three Die Hard films was available in stores - so although the promotion of Live Free or Die Hard takes precedence, all four films as well as the franchise itself are being marketed here.

The second subsection of A Nation For Change is "The Issues," which, in keeping with the political theme of the website, addresses McClane's take on various problems facing the contemporary Unites States. McClane's platform is divided into five headings: Terrorism, Health Care, Technology, Patriotism and Culture. Each section features an explanation of McClane's approach to the issue and one or two related quotes (again, the majority of which are from Live Free or Die Hard). For example, under Terrorism:

\section{MCCLANE WAS FIGHTING THE WAR ON TERROR BEFORE IT EVEN HAD A NAME - AND HE'S PROVEN HE CAN WIN IT.}

In his own words... On terrorism: "It's always about the money."

On putting himself in an extremist's shoes: "Nine million terrorists in the world and I gotta kill the one with feet smaller than my sister."

Throughout this section, McClane's experience, anti-elitism and toughness are brought to the fore, but in the context of humorous wise-cracks from the character. In many ways, this ties into and promotes the popular conception of the Die Hard franchise: McClane is a no-nonsense, politically incorrect everyman who is tough enough to deal with anything the world throws at him, with a grin on his face and a gun in his hand. Additionally, 
McClane's defiance of bureaucracy and wishy-washy politicians features prominently throughout the Die Hard canon, and the site places a strong emphasis on his ability to take action and "get the job done." As such, the Issues section reinforces McClane's status as a fictional "badass," while simultaneously mapping the fictional, heroic universe of Die Hard onto the drama and bombast of the real-world politics and electioneering for the purpose of self-reflexive parody.

As noted above, in addition to these informational sections, A Nation For Change features several pseudo-interactive activities for visitors. The website allows visitors to send an automated e-mail to friends summarizing the McClane campaign, and features a petition to have McClane put on the 2008 presidential ticket — which in actual fact asks visitors to sign up for updates about Fox products and "exclusive offers." Visitors can also download posters, bumper stickers and embed an image linking back to A Nation For Change on their own websites. On the main page of the site is an embedded video in which seemingly "real" interviewees on city streets offer testimonials for McClane's campaign by answering the question, "Why do you think John McClaine [sic] should be the next President?" The answers reflect the same parodic tone found across the site. "Because he's hot," is the most common answer, with another interviewee adding that “...he's bald, he knows how to use a gun, and he's cool." One young woman reappropriates a Chuck Norris "fact," suggesting that "John McClane's tears cure cancer — too bad he's never cried." ${ }^{\text {"21 }}$ The strange intersection of two Internet memes aside, the video is very much in keeping with the overall tone of the site, humorously combining a

${ }^{121}$ Chuck Norris "facts" are another Internet meme, and are a series of jokey one-liners about Chuck Norris' various uncanny powers and abilities. See http://www.washingtonpost.com/wpdyn/content/article/2006/01/02/AR2006010200282.html for further information about the meme and examples. 
real-world trope of presidential campaigns (the testimonial video) with the fictional world of Die Hard in order to promote the new DVD and the franchise at large.

Also on the main page of the site is a poll that asks visitors to vote for McClane's running mate. Four choices are available to be ranked, with a quote or catchphrase from each: "The Terminator" (with a photo of Arnold Schwarzenegger as governor of California), Matthew Farrel (with a photo of actor Justin Long at the Live Free or Die Hard premiere), Keifer Sutherland as Jack Bauer of 24 (2001-) and a recent photo of Cybill Shepard as "Madelyn" (sic) Hayes from Moonlighting (1985-1989). The running mate poll is fascinating in its intertextuality, and is perhaps the most interesting and complex aspect of the site's approach to marketing, with each potential running mate representing a different alignment between John McClane and another fictional/real character/public personality. The Terminator option, for example, clearly aligns McClane and the Die Hard Franchise - generally considered to be one of the great action hero franchises of the late 1980 s and early $1990 \mathrm{~s}$ - with Schwarzenegger and the Terminator franchise, perhaps the most iconic of those hard-bodied action heroes. This reinforces nostalgic attachment to the Die Hard franchise and extends this classic status to the newest film. Schwarzenegger's real-world political career (which is often ironically conflated with the fictional characters he has portrayed), brings an additional layer of referentiality to the poll by ironically implying (as one of the video testimonials does) that McClane/Bruce Willis has equal claim to political office. The Matt Farrel option is less ironic and more directly related to Live Free or Die Hard - the Farrel character is, after all, McClane's sidekick in the film and a key aspect of the film's marketing to 
younger audiences - but is also apparently one of the least popular options on the poll. Jack Bauer, on the other hand, is easily the most highly rated option, perhaps due to his analogous terrorist-battling experience, or simply due to the popularity of 24 . In this case, as opposed to the nostalgic alignment with the Terminator franchise, Bauer represents a new, popular hero-character, and suggests that McClane in Live Free or Die Hard is every bit as strong and relevant a hero as his modern day television counterpart. The Maddie Hayes option has relatively little to do with Live Free or Die Hard and everything to do with Bruce Willis' star persona. The coy reference to Willis the actor's co-star from Moonlighting, his first major role, in context of McClane, his career-making turn in the Die Hard franchise, primarily serves to further the website's parodic, tonguein-cheek tone, straying far from the established Die Hard canon. However, the reference also indicates how franchise discourse overlaps and interact with other networks of meaning such as star persona.

The "A Nation For Change" campaign is first and foremost a marketing device, designed to promote the Live Free or Die Hard DVD release specifically, and the Die Hard franchise more generally. In doing so, the site clearly presents McClane as the nononsense, wisecracking American cowboy familiar to fans of the Die Hard films, and attempts to position Live Free or Die Hard as a legitimate contribution to the canon. The dogmatic, right wing rhetoric of McClane's violent approach to America's problems is balanced with a strong dose of goofy irony that, although never genuinely critical or satirical, pokes good-natured fun at the tropes of political conservatism and of action hero movies. Although perhaps referencing John McCain's bid for the Republican nomination 
on some underlying level (the assumption being that McClane, like McCain would be running as a Republican), the connection is never made explicit. It is important to note that McCain would not become the official nominee until four months after the site went live, and the site has never been updated. The site generally emphasizes the escapist fun of action movies over intensity, and is kept to a PG-rated minimum of profanity and violence in keeping with the theatrical release of Live Free or Die Hard. As noted above, much of the humour on the site is derived from the comic juxtaposition of the determinedly unrealistic fictional world of Die Hard and the bureaucratic real world of politics, and from self-reflexive jokes about the franchise itself. The site pleads for a leader "with strength, experience and stubble" and suggests that "you'd have to be insane to attack a country that has McClane for president." Insofar as marketing strategy is concerned, it seems that A Nation For Change is intended by Fox to simply keep the focus on the franchise, rather than explicitly marketing any one product, encouraging visitors to nostalgically recall the Die Hard films and look into the new film on DVD while enjoying the self-referential humour of the site.

Fox's site is not the only instance of the McClane for President meme, and a variety of other "unofficial" versions also exist and circulate on the Internet. The most fully articulated of these is "Vote John McClane," a third-party website specializing in John McClane campaign merchandise. ${ }^{122}$ The differences between Vote John McClane and A Nation For Change are immediately apparent upon visiting the "unofficial" site:

122 "McClane 2008," http://www.votejohnmcclane.com/. This site also features an associated MySpace page, at http://www.myspace.com/votejohnmcclane. 
emblazoned across the header of the site, against an American flag background, is McClane's uncensored "Yippee Ki-Yay, Motherfucker!" catchphrase. ${ }^{123}$ Further demonstrating the difference in approach, the main page of the website answers the question, "Why John McClane?"

"Why Not? John McClane is a Badass. He's an American. He doesn't take shit from terrorists. He smokes. He crawls through air conditioning ducts. He's a lover AND a fighter. So, shouldn't we, The United States of America, have someone like John McClane in office? He would be the perfect leader of the free world. He would bitch-slap everyone that pisses him off. He won't lie to our faces, he'll tell it like it is. He wears his heart upon his sleeve, when he's wearing sleeves. He's not afraid of a little blood. Whether it's his or a shitty terrorist's. He has a squinty seriousness about him. He's got a tattoo, too. Yeah, he's a goddamn American and he's goddamn proud of it. America needs John McClane. So, citizens of the free world... rise up and embrace the future of America. John McClane. He takes shit from no one. Ever."

This emphatic, profanity-laced rhetoric is found throughout the site and, like the header, indicates that the vision of John McClane and the Die Hard franchise presented by this site is decidedly unlike the "official" Fox version. The vulgarity and explicit references to McClane's anger and violence are in stark contrast to the PG-rated A Nation For Change. This version of McClane, though invoked with no less irony, is less wisecracking and more vicious, and the emphasis is clearly on his physical capacity for deadly, entertaining violence rather than jokily framing McClane's attitudes as campaign policies (as in the Issues section of A Nation For Change). According to Vote John McClane, experience as an action hero is the only experience necessary: elsewhere on the site, visitors are warned, "Let him lead us into the future. It's either LET HIM or he'll do it anyway [...]

${ }^{123}$ An entirely separate paper could be written on the many and varied spellings of this catchprase. 
The guy jumped off of a sky scraper with a fire hose tied around his waist for fuck's sake!"

Vote John McClane is evidently not concerned with promoting DVD sales - the site is owned and operated by an independent group unaffiliated with Fox. Rather, the site is designed entirely to promote the online sale of other, unlicensed merchandise - $t-$ shirts, buttons, bumper stickers and even election-style lawn signs. Not bound by the same rules as Fox's Intellectual Property Development department, the site is free to curse extensively (although the merchandise is available in "clean" versions also), use less-than-flattering images of McClane, and even make Hans Gruber, the principal villain from Die Hard, McClane's seemingly contradictory running mate. ${ }^{124}$ Additionally, this freedom from a corporate mandate allows Vote John McClane to completely deemphasize Live Free or Die Hard, and to focus almost entirely on moments and images from the first film in the franchise. Rather than attempting to create a continuous history for the McClane character, the site instead isolates the most canonized text of the franchise and centers its discourse on nostalgic association with that film to sell merchandise. This represents one of many different pragmatic instances of the Die Hard franchise, mounted for a very specific purpose by this particular group of users.

Another significant difference between the "official" Fox version of the McClane for President meme and this "unofficial" site is that Vote John McClane freely and openly references John McCain's presidential campaign. Unlike A Nation For Change, Vote John McClane first went live in September 2008, well into McCain's campaign and long after

${ }^{124}$ From the site: "Gruber was a terrorist. Who better to know how to get into the minds of terrorists, than Gruber. [...] Gruber learned his lesson from McClane, now it's The World's Turn! See, who says arch enemies can't one day be buddies?!" 
his official nomination. Specifically, the branding of the merchandise sold on the site directly parodies McCain's campaign logo, using an analogous typeface for "McClane" and the same nautical star symbol. ${ }^{125}$ While there is no explicit mention of McCain's campaign beyond this connection, the obvious visual parody inevitably colours the text on the site. McCain's carefully groomed public and media image as a "straight shooter" and a "maverick" is linked to McClane's status as an authentic American cowboy: "Show your support for the greatest, most honest, badassest [sic] Presedential [sic] Candidate this country has ever seen! He'll thank you for it by kickin' more terrorist ass than ever before." In many ways, the McCain campaign is bound up in the same American mythology as McClane and the Die Hard franchise, and so the ironic alignment between the two goes beyond the similarity of their names. The fictional McClane is what McCain purports to be, but more so. If the humour of A Nation For Change is based on recontextualizing the action hero discourse of Die Hard as real-world political rhetoric, the humour of Vote John McClane is based around the ironic conflation of McClane and McCain, and the juxtaposition of action hero violence and profanity-laden rhetoric against real world political discourse. This, I would argue, reflects a different conception both of McClane and of the Die Hard franchise at large. ${ }^{126}$

Although Vote For John McClane is by far the most formalized seller of McClane for President merchandise, a host of similar products are available from other sites. Most

125 The McClane/Gruber merchandise similarly references the McCain/Palin logo.

${ }^{126}$ Intertextuality informs the humour in many instances of this meme: Vote For McClane also features a reference to the Chuck Norris "facts" meme, suggesting that "even Chuck Norris thinks McClane is a total badass." The site also references a popular scene from the cult comedy Office Space (1999), when describing McClane 2008 buttons: "it doesn't get any better than McClane flair! You do want to express yourself, right?" 
of these are hub sites where users can have generic clothing and objects branded with custom images and slogans based on uploaded files. Zazzle.com and CafePress, two popular examples of such sites, each feature a dozen or more designs drawing on the same basic concept. Some of these products are very much in keeping with A Nation For Change and Vote John McClane, creating humour by merging or contrasting the Die Hard franchise and politics. A number of these feature home-made designs, mostly comprised of simple slogans and occasionally unprofessional-looking logo designs involving American flags. ${ }^{127}$ Others faithfully and not-so-faithfully recreate the McCain logo along the same lines as the Vote John McClane merchandise. ${ }^{128}$ Although the majority of these feature some variation of McClane's most famous catchphrase, a number substitute it for other references to the films and franchise, such as "McClane: Now I have a machine gun," and "John McClane '08: Change or Die Hard." The tongue-in-cheek intertextuality of the websites discussed above is also apparent in certain designs, such as "McClane/Bauer '08: Come out to the coast, we'll set up a perimeter," again referencing 24 (and combining famous quotes from each). ${ }^{129}$ One initially perplexing design, "McClane/Palin '08: Yippie Ki Yay and I'll have your spam. I love it. I'm having spam spam spam spam spam spam spam baked beans spam spam spam and spam!” simultaneously references the McCain/Palin campaign, Die Hard and Monty Python,

\footnotetext{
127 http://shop.cafepress.com/design/20971133, http:/shop.cafepress.com/design/25993657, http://shop.cafepress.com/design/27605353, http://signs.cafepress.com/item/change-or-die-hard-johnmcclane-for-president/227680896, http://www.zazzle.com/iohn mcclane in 08 shirt235703290639987920 , and http://www.zazzle.com/elect 2008 john mcclane shirt235131299421976000 .

128 http://www.cafepress.com/mcclane2008, http://t-shirts.cafepress.com/item/john-mcclane-2008-electionshirt/266831335, http://www.zazzle.com/mcclane 08 3_shirt-235349723694133702, http://www.zazzle.com/mcclane 082 shirt-235537923466174920, and http:/www.zazzle.com/mcclane 08 shirt-235160746026974591.

${ }_{129}$ http://www.zazzle.com/mcclane_bauer for_prez_vice_prez_shirt-235888762785597566.
} 
again combining well-known catchphrases and implying that John McClane and Michael Palin are running mates. ${ }^{130}$ Each of these designs places McClane and the Die Hard franchise in a slightly different discursive context, whether independently or in relation to other texts and franchises, as in the latter examples.

Perhaps unsurprisingly, a handful of these custom designs go beyond irony for its own sake and make explicitly partisan political statements, using negative comparisons between John McCain and the Die Hard hero to create anti-McCain slogans. One product line, called "No More Cowboys," features the text, "When John McClane said 'Yippee ki yay' it was cool. When John McCain says it... it's scary." ${ }^{\text {"131 }}$ This particular example highlights a conception of the Die Hard franchise (and of action movies more generally) that suggests that the politically conservative, violent approach to problem-solving is appropriate, entertaining and even valuable within the fictional universe of the franchise, but is inconsistent with real-world values. In this context, the perceived ideological similarities between McClane and McCain are used to directly attack the political right wing. Another pair of designs, by contrast, suggest that "In 2008, we wanted John McClane... but we got John McCain," and "John McClane Die's [sic] Hard... John Mccain [sic] hardly alive coincidence? [sic]," the former of which goes so far as to include an unflattering, exhausted-looking image of McCain himself. ${ }^{132}$ These designs, rather than aligning McClane with McCain in order to criticize McCain's ideology, instead contrast McClane's perceived power and virility against McCain's old age and apparent infirmity. In this case, McClane's physicality and the ideology of the Die Hard

${ }_{130} \mathrm{http} / /$ shop.cafepress.com/design/29900503.

13) http://www.cafepress.com/antimccainshop2.

132 http:/www.zazzle.com/john mcclane not john mccain t shirt-235490677131675494, http://www.zazzle.com/john mcclanedies hard_shirt-235790664847139159. 
films are held up as an ideal that McCain fails to attain. Although both designs are critical of McCain, they use the franchise in very different ways and for different political purposes: in one case, McCain is too much like McClane; in the other, he is not enough like McClane.

Not all "unofficial" instances of the meme are centred around merchandise. A number of blog posts and independently-maintained websites also propose McClane for President, as well as numerous links and references to both "official" and "unofficial" iterations of the meme posted on blogs and in online forums and communities. Some of these simply involve homemade campaign images and slogans similar to those described above. ${ }^{133}$ The URLs mcclane2008.com and johnmcclane2008.com both link to a single image of McClane in action, with the header "John McClane for America." Other slogans such as "Finally, someone who gets the job done," and "McClane 2008: He killed a helicopter with a car" indicate a non-partisan, comic approach to the meme, not unlike A Nation For Change and Vote John McClane - again, some of these directly reference the McCain logo while others do not. The humour tends to revolve around McClane's action movie "credentials" (killing helicopters with cars, walking on glass with bare feet, etc.) rather than any kind of political satire. Others integrate McClane comments into musings about the election and about McCain, often with reference to McCain's "maverick" persona, and usually as a negative comparison. ${ }^{134}$ Additionally, in certain cases McClane

${ }_{133}$ http//www.toddcarruth.com/images/mcclane08.jpg, http://www.organicmechanic.org/2008/08/johnmcclane-for-president/, http:/www.inquisitr.com/4011/john-mcclane-2008/, http://www thetaoofmakingmoney.com/2008/09/25/576.html, http://codenameblogtastica.blogspot.com/ 2008/02/another-political-post.html, http:/www.mcclane2008.com/, http://johnmcclane2008.com/.

${ }_{134} \mathrm{http} / / \mathrm{blogs}$.westword.com/demyer/2008/08/john mcclane for president.php, http://toddswift.blogspot.com/2008/09/mccain-vs-mcclane.html, http://www.shortlist.com/funnystuff/article/john-mccain-vs-john-mcelane. 
and McCain are compared directly using charts. One of these presents a genuinely conservative interpretation of Die Hard, suggesting that McCain isn't right-wing enough, questioning his manliness and abilities. ${ }^{135}$ "John McCain: Pretends to be a national hero. John McClane: Real national hero [...] John McCain: Says we shouldn't be afraid if a terrorist is president of America. John McClane: Kills terrorists for fun." The latter of these comparisons in particular betrays a strongly conservative bent, as it references McCain's comment at a rally that Americans need not be afraid of a Barack Obama presidency, suggesting that Obama is in fact a terrorist. ${ }^{136} \mathrm{~A}$ similar chart instead draws humorous parallels between McCain and McClane: both are "Still going strong, even after franchise [sic] is 'outdated'," referring to the Republican party, Bush's presidency and McCain's age, both have "hot daughters," are "Pals with Schwarzenegger" and kick ass while taking names. ${ }^{137}$ Here, the meme is played for satire without explicitly promoting any specific political agenda.

This non-partisan satirical approach can also be found in a wide variety of videos posted to sites like YouTube and AOL Video. One video, featuring amateur actors portraying McClane, Sarah Palin and CBS News Anchor Katie Couric, blends current events with the Die Hard franchise. It depicts McClane saving Palin from Couric's microphone, and includes parodic reenactments of specific scenes from Die Hard. ${ }^{138}$ Similarly parodic is a fake trailer for "Vote or Die Hard," which also reenacts famous scenes from the franchise with an election twist, as McClane is unexpectedly named the

${ }_{135}$ http://il48.photobucket.com/albums/s12/giannidough/mccainversusmcclane.jpg.

${ }_{136} \mathrm{http}: / /$ politicalticker.blogs.cnn.com/2008/10/11/mccain-to-crowd-dont-be-scared-of-obama-presidency/.

${ }_{137} \mathrm{http} / /$ /nocturne.noctalis.com/codex.cgi?Die Hard 08 John_McCain vs_John McClane.

${ }^{138}$ http://www.youtube.com/watch? $v=30$ trRZ6ucLg\&feature-related. 
Republican candidate. ${ }^{139}$ "Come out to the convention, we'll get together, have a few laughs," McClane bitterly quips. Along the same lines are a song about how McClane should run for president and a rap by a comedian in which McCain's career experience is confused with McClane's. ${ }^{140}$ One of the most technically accomplished examples is an entry for a contest on the popular news parody show The Colbert Report, which challenged viewers to green-screen a clip of John McCain into other footage. In this entry, McCain's head is superimposed onto McClane's body while he threatens Gruber in a climactic scene from Die Hard. ${ }^{141}$ Other videos simply recut footage from the Die Hard franchise into campaign ads for McClane's bid. ${ }^{142}$ Other videos draw direct analogy between McCain's campaign and the Die Hard franchise. One of these edits news footage of McCain and various current events to sync with audio clips from the Die Hard films, as a trailer for the fictional film "Vote Hard." ${ }^{\text {"143 }}$ More explicitly critical of McCain is "Die Hard: In Office," which pokes fun at McCain's age and implies that if elected he may die while still President. ${ }^{144}$ Also framed as a fake movie trailer, it presents McCain as the hero of an action movie (also starring Schwarzenegger and Chuck Norris) in which he must fight against the Grim Reaper to defend himself and the White House. In keeping with the YouTube aesthetic, all of these videos are short (under five minutes), home made, absurd and irreverent, and tend to treat Die Hard as an ironic pop culture artifact, rather than as a genuinely good or valuable object of culture, positioning McClane as a

\footnotetext{
139 http//www.youtube.com/watch? $\mathrm{v}=$ uavHzMUo3NO\&feature-related.

$140 \mathrm{http} / / \mathrm{www}$ youtube.com/watch? $\mathrm{v}=$ oymPqemQQ3M, http://www.youtube.com/watch? $v=$ mzmclY9SSS4\& feature $=$ related.

141 http://www youtube.com/watch? $\mathrm{v}=\mathrm{DeU}-2$ EmGYK Y\& feature=related.

142 http://www.youtube com/watch?v=9KdsPzoHQs, http://www.youtube.com/watch? $\mathrm{v}=\mathrm{Hs} \mathrm{kgWhn} 9 \mathrm{QM}$.

$143 \mathrm{http}: / \mathrm{www}$.youtube.com/watch? $\mathrm{v}=\mathrm{hYMlvBu} 8 \mathrm{MQ} \&$ feature=related.

144 http:/www.youtube.com/watch? $y=$ HMlag9Up464\& feature=related.
} 
ridiculous, campy action hero much in the same vein as Chuck Norris parodies.

It should be abundantly clear the degree to which this relatively small Internet meme (compared to Chuck Norris "facts," for example,) nevertheless represents a significant body of discourse. ${ }^{145}$ The McClane for President Internet meme shows that many different conceptions of the Die Hard franchise exist, which are by no means subject to any one specific "official" version or canon. Where the "official" Fox version of the meme demonstrates a clear drive to place Live Free or Die Hard in continuity with its predecessors as the current principal Die Hard text, the various "unofficial" versions almost invariably avoid Live Free or Die Hard in favour of the earlier films in the franchise. By the same token, there is a widely varying range of treatments of the violence and ideology of the McClane character, from the fun, entertainment-oriented "official" version, to the campy extreme virility depicted by others, to the much more explicitly violent and right-wing McClane described elsewhere. The franchise network contains a multiplicity of McClanes, and is composed of discourses, no matter how ephemeral, that define and redefine Die Hard constantly. I hope to have shown in this chapter that such ephemera is very much engaged with and a part of the larger discursive network, and cannot be divorced from the franchise. As we have seen with franchise apocrypha, by including seemingly marginal aspects in our understanding of a franchise, and situating them in relation to other parts of the network, we can effectively account for the occasionality and varying pragmatics of franchise discourse and develop nuanced analyses.

${ }^{145}$ By way of comparison, "McClane president" yields 77,900 Google results, while "Chuck Norris facts" yields $1,120,000$. (Source: http://www.googlebattle.com/index.php? domain $=\mathrm{McClane}+$ President\&domain $2=$ Chuck + Norris + facts\&submit $=$ Go!). 


\section{CONCLUSION}

New questions will be heard:

"What are the modes of existence of this discourse?"

"Where does it come from; how is it circulated; who controls it?" 146

In this quote, also cited by James Naremore in More Than Night, Foucault posits a new avenue of inquiry into the processes of meaning-making, past the "tired repetitions" of authorship, authenticity and originality. ${ }^{147} 1$ have already alluded to the fact that the reinvention of media franchises as a concept presented here can be situated within a larger philosophical context. As Altman notes in his conclusion to Film/Genre, his approach to genre studies can be seen as part of a "renewed general theory of meaning" based on the discursivity of all things. ${ }^{148}$ In addition to contemporary thinking on genre, other concepts such as authorship, stardom and nation are also being theorized as discursive systems of meaning, as opposed to fixed objects. Marjorie Garber's recent book, Shakespeare and Modern Culture, argues that Shakespeare can be seen as a similarly discursive construct, rather than an author in the conventional sense, created and re-created to mean many different things in an infinite number of instances; Marc Raymond's dissertation, "Martin Scorsese and Film Culture: Radically Contextualizing the Contemporary Auteur" makes similar claims about the famous director. Andrew Higson's work on national cinema studies also illuminates an approach to the concept of nation as a discursive, rather than fixed, object. In all these cases, the meaning of the concepts in question is discursively constructed and highly contingent.

${ }^{146}$ Michel Foucault, "What Is An Author?" in Language, Counter-Memory, Practice: Selected Essays and Interviews by Michel Foucault, ed. Donald F. Bouchard (Ithaca, New York: Cornell University Press, 1977), 138.

147 Ibid.

148 Altman, 215. 
As I have argued throughout this thesis, media franchises are no different, and represent a comprehensive range of elements, positioned and defined through an equally wide range of discourses. As such the study of franchises much be acutely aware of the occasionality and contextual function of these elements, making discourse, not individual texts, the primary object of study. By the same token, the dominant discourses of canon and continuity must be acknowledged to be just that, illusory discursive constructs, and analyzed as such. Beyond canon and text, there lies an expansive array of other discourses that are no less meaningful and significant to the franchise in certain contexts. Our understanding of media franchises, therefore, must include any and all non-fictional, non-canonical and non-textual apocrypha and ephemera in order to fully account for that occasionality. By theorizing media franchises and similar discursive constructs in this way, we can seriously consider how these constructs are deployed and understood, and how the relationships between them form a much bigger and denser network.

Let us return to the metaphor of an imaginary web, in which countless nodes in the franchise network are connected by countless threads of discourse, that define and construct the whole in a multitude of different ways. Now, consider that this web is not alone in our imagination. Other webs exist also in a similar form - other franchises, genres, stars, authors, nations, cultures, technology, art, politics, and on and on. This immense system of webs intersects and interacts with itself through infinite threads of discourse in much the same manner as the individual nodes within each web. What are the modes of existence of the discourse of Superman? The Superman franchise is fundamentally defined by the star status of Christopher Reeve and Kevin Spacey, the 
authorship of Bryan Singer, Richard Donner and Joe Shuster, a century of shifting American ideology and culture, Canadian notions of ownership over the character via Heritage Minutes, Tarzan, competing superheroes from Marvel Comics, the science fiction film, the action-adventure film, the larger superhero genre and a host of Superman texts, canons and continuities across many media, toys, $t$-shirts and Halloween costumes, childhood drawings of Superman and fan films on YouTube, lifetimes spent debating the hero's powers, a million moments of fandom, a trillion dollars in profits, and an academic at a comic con concerned with Superman's representation of masculinity. Superman is not a singular object, but a multiplicity of overlapping discourses, and part of a much, much larger network through which meaning is constructed. What I have proposed in this thesis is a framework for the analysis of a concept, the media franchise, that guides the production of meaning. In doing so, I hope to have asked some new questions that can be incorporated into our investigation of that great imaginary web of meaning. 


\section{BIBLIOGRAPHY}

Altman, Rick. Film/Genre. London, England: British Film Institute, 1999.

Baker, Chris. "Meet Leland Chee, the Star Wars Franchise Continuity Cop." Wired. http://www.wired.com/entertainment/hollywood/magazine/16$09 / \mathrm{ff}$ starwarscanon?currentPage $=$ all.

Biology in Science Fiction. "Star Wars and the Midi-Chlorian Menace." http://sciencefictionbiology.blogspot.com/2007/06/star-wars-and-midi-chlorianmenace.html.

Blair, Roger D. and Francine Lafontaine. The Economics of Franchising. New York: Cambridge University Press, 2005.

Bloom, Harold. A Map of Misreading. New York: Oxford University Press, 1975.

Brooker, Will. Using the Force: Creativity, Community and Star Wars Fans. New York: Continuum, 2002.

Burton, Bonnie. “'Family Guy' Creator Reveals Star Wars Cred." Star Wars. http://www.starwars.com/community/news/rocks/f20070921/index.html.

Chef Elf. "The Nitpicker's Guide to The Star Wars Holiday Special." http://chefelf.com/starwars/holiday intro.php.

Coogan, Peter. Superhero: The Secret Origin of a Genre. Austin, Texas: MonkeyBrain Books, 2006.

Dassanowsky, Robert. "Casino Royale." Film Reference. http://www.filmreference.com/Films-Ca-Chr/Casino-Royale.html.

De Vany, Arthur S. Hollywood Economics: How Extreme Uncertainty Shapes the Film Industry. London, England: Routledge, 2004.

Dittmer, Jason. "Retconning America: Captain America in the Wake of WWII and the McCarthy Hearings." In The Amazing Transforming Superhero!, edited by Terrence R. Wandtke. Jefferson, North Carolina: McFarland \& Company, 2007.

Domain Tools. "Whois Record for Anationforchange.com." http://whois.domaintools.com/anationforchange.com.

"Expanding Our Mission." http://www.hanshootsfirst.org/mission.aspx. 
Foucault, Michel. "What Is An Author?." In Language, Counter-Memory, Practice: Selected Essays and Interviews by Michel Foucault, edited by Donald F. Bouchard. Ithaca, New York: Cornell University Press, 1977.

Fried, Brian. "Radioactive Kryptonite: The Industrial Factors Behind the Use of Origin Tales in Comics-Based Films." MA Thesis, Carleton University, 2001.

"Han Shoots First." http://www.hanshootsfirst.org/.

Helmer, Christine and Christof Landmesser. "Introduction: A New Biblical-Theological Approach to the Unity of the Canon." In One Scripture or Many? Canon from Biblical, Theological, and Philosophical Perspectives, edited by Christine Helmer and Christof Landmesser. New York: Oxford University Press, 2004.

I-Mockery. "The Star Wars Holiday Special." http://www.i-mockery.com/minimocks/starwars-holiday/.

IGN. "Perfect Dark." http://uk.ign64.ign.com/articles/153/153906pl.html.

International Franchise Association. "Frequently Asked Questions About Franchising." http://www.franchise.org/industrysecondary.aspx?id=10008.

Jefferies, Dru H. "Convergence Culture and the Caped Crusader: Batman and the Environment of New Media." Paper presented at the annual Film Studies Association of Canada Graduate Conference, University of Toronto, February 1517,2008 .

Jenkins, Henry. "Transmedia Storytelling 101." Confessions of an Aca-Fan. http://henryjenkins.org/2007/03/transmedia_storytelling_101.html.

Jenkins, Henry. Convergence Culture: Where Old and New Media Collide. New York: NYU Press, 2006.

Kathleen Cullen Fine Arts, "Mark Chamberlain (American 1967)," http://www.artnet.com/Galleries/Artists detail.asp? $\mathrm{G}=$ \& gid $=423822183 \&$ which $=$ \&aid $=424157172$.

Kraus, Daniel. "The Phantom Edit: How one "Star Wars" fan nearly fixed the "Episode 1" disaster, and why George Lucas is indirectly stoking another kind of digital revolution." Salon. http://archive.salon.com/ent/movies/feature/2001/11/05/phantom_edit/index.html.

"Live Free or Die Hard." http://www.livefreeordieharddvd.com/. 
Maxwell, Daryn. "Tomorrow Never Dies." http://www.fanfiction.net/s/699242/1/Tomorrow_Never_Dies.

"McClane 2008." http://www.votejohnmcclane.com/.

Meehan, Eileen. "Holy Commodity Fetish, Batman! The political economy of the commercial intertext." In Hollywood: Critical Concepts in Media and Cultural Studies, edited by Thomas Schatz. New York: Routledge, 2004.

Miller. Toby. "Cinema studies doesn't matter; or, I know what you did last semester." In Key Frames: Popular Cinema and Cultural Studies, edited by Matthew Tinkom and Amy Villarejo. New York: Routledge, 2001.

Naremore. James. More Than Night: Film Noir In Its Contexts (Updated and Expanded). Berkeley: University of California Press, 2008.

Neale, Steve. Genre and Hollywood. New York: Routledge, 2000.

Newgen, Heather. "Superman Returns Screenwriters Dougherty and Harris." Superhero Hype!. http:/www.superherohype.com/news/supermannews.php?id=4393.

Schatz, Thomas. "The New Hollywood." In The Film Cultures Reader, edited by Graeme Turner. New York: Routledge, 2002.

"Should Superman Go Dark?" http://splashpage.mtv.com/2008/08/26/should-supermango-dark-we-ask-kevin-smith-jeph-loeb-and-other-comic-creators/.

Silent7. "Die Hard DVD: Elect John McClane." http://www.silent7.com/index.php?/interactive/die-hard-dvd-elect-john-mcelane/.

Snider, Mike. "'Robot Chicken' digs its satirical talons into 'Star Wars'." USA Today. http:/www.usatodav.com/life/television/news/2007-06-12-robot-chicken_N.htm.

"Star Wars Fan Movie Challenge - Guidelines." http://www.atom.com/spotlights/starwars/challenge/infoguide.html.

Sterngold, James. "Sony Pictures, in an accord with MGM, drops its plan to produce new James Bond movies." New York Times, March 30, 1999.

"Superman Returns." http://supermanreturns.warnerbros.com/.

"The Origins of the Black Knight."

http://www2.warnerbros.com/batmanbegins/productionnotes/. 
The Star Wars Holiday Special. "Official Production Notes." http://www.starwarsholidayspecial.com/text/production notes.htm.

Thompson, Kristin and David Bordwell. Film History: An Introduction. Madison, Wisconsin: McGraw Hill, 2003.

Thompson, Kristin. The Frodo Franchise: The Lord of the Rings and Modern Hollywood. Berkeley, California: University of California Press, 2007.

Trautman, Ludovic. "A Timeless Character Born Within History: The Paradox Of James Bond In The Novels And On The Screen." Paper presented at the annual Film Studies Association of Canada Graduate Colloquium, University of Alberta, Edmonton, February 13-15, 2009.

Verevis, Constantine. Film Remakes. New York: Palgrave Macmillan, 2005.

Wasko, Janet. How Hollywood Works (London, England: SAGE Publications Ltd., 2003) 7-8.

Wikipedia. "Internet meme." http://en.wikipedia.org/wiki/Internet meme.

Wookieepedia. "Han shot first." http://starwars.wikia.com/wiki/Han shot_first.

Wyatt, Justin. High Concept: Movies and Marketing in Hollywood. Austin, Texas: University of Texas Press, 1994.

"Yippie Kay Yay, America!." http://www.anationforchange.com/. 